\title{
LIGHT SCATTERING IN LIQUIDS
}

\author{
By R. M. Langer ${ }^{1}$ and William F. Meggers
}

\section{ABSTRACT}

The theory of light scattering is discussed with special reference to the following points: Comparison between coherent and incoherent scattering, variation of intensity with frequency of exciting light, nature of frequency shifts, and location of energy levels which play a rôle.

An efficient experimental arrangement for investigating the spectra of mercury arc light scattered by liquids is described in detail, and numerical data are given for the modified lines observed for benzene $\left(\mathrm{C}_{6} \mathrm{H}_{6}\right)$, toluene $\left(\mathrm{C}_{6} \mathrm{H}_{5} \mathrm{CH}_{3}\right)$, chloroform $\left(\mathrm{CHCl}_{3}\right)$, and carbon tetrachloride $\left(\mathrm{CCl}_{4}\right)$. From the wave numbers of the modified and unmodified lines the frequency shifts $\left(\mathrm{cm}^{-1}\right)$ characteristic of the liquids are determined as follows: $\left(\mathrm{C}_{6} \mathrm{H}_{6}\right) 605.7,848.6,992.1,1177.3,1585.2$, 1604.5, 2946.9, 3045.4, 3060.1, 3185.0?; $\left(\mathrm{C}_{6} \mathrm{H}_{5} \mathrm{CH}_{3}\right)$ 217.3, 521.0, 622.6, 785.8, $1003.3,1031.3,1208.7,1379.4,1604.5,2920.2,3053.9$; $\left(\mathrm{CHCl}_{3}\right)$ 261.1, 365.8, 668.4, 760.1, 1215.0, 3018.7; $\left(\mathrm{CCl}_{4}\right) 218.8,313.9,459.3,758.1,789.2,1539$. Comparison of these results with the available data on infra-red absorption spectra shows no simple, direct correspondence, and the exact connection of constants derived from the study of light scattered by complex molecules with other molecular data remains obscure at present.

\section{CONTENTS}

I. Introduction

Page

II. Theoretical

III. Experimental

711

IV. Results

1. Mercury spectrum

2. Benzene

3. Toluene

4. Chloroform

5. Carbon tetrachloride

V. Discussion

\section{INTRODUCTION}

A large measure of the interest attaching to the recent experiments on incoherent scattering, first observed by Raman and Krishnan, ${ }^{2}$ is due to the theoretical connection between the frequency shifts in scattered light and the energy differences among various possible states of the scattering system. Experimenters tried at first to connect every $\Delta \nu$ with some absorption line of the system and sought mainly in the infra-red spectrum for such lines. Encouraged by some coincidences the correlation was forced in many cases where agreement was only approximate and even large discrepancies were attributed to experimental errors. The theory discussed from a point of view, such as the one developed later in the present paper, shows that the connection is by no means so simple and direct. The 
discussion indicates that there is a much more interesting and important relation between the shifts in scattered light and the energy states, of such a nature that the infra-red (and other) investigations would be nicely supplemented by light-scattering studies and vice versa.

Work in the infra-red is difficult experimentally and the data obtained are so very complicated that in spite of their extreme interest no considerable systematization has been effected. If the incoherent scattering proves as helpful as it promises at present the enthusiasm with which the first workers ${ }^{3}$ took up the subject will be amply justified by the advances which must follow.

The hope that the data obtained from light-scattering experiments may prove important in the study of complex molecules makes it seem desirable to get such data with greatest possible accuracy. Unfortunately the publications which have appeared on this subject have disregarded practically all the requirements of precision and have devoted themselves mainly to more or less qualitative descriptions of the phenomena. Because of this we have thought it worth while to report some of the measurements made by us during the past year at the Bureau of Standards. In these measurements an attempt has been made to get the best numerical values possible with the apparatus available.

\section{THEORETICAL}

In designing an apparatus for scattering experiments it is advisable to consider the nature of the phenomenon from the theoretical side. There is so far no significant experimental evidence that the quantum mechanical description of the process of incoherent scattering after the method of Dirac ${ }^{4}$ is faulty in any observable detail. The formula for such scattering can be derived by wave or matrix mechanics or with the help of intuition from the correspondence principle as was originally done by Kramers and Heisenberg. ${ }^{5}$

The energy scattered per second by $N_{k}$ molecules in some particular state, $k$, polarized parallel ${ }^{6}$ to the incident radiation of the same frequency, $\nu$, and coherent with the incident radiation is

$$
S^{c}{ }_{k}=\frac{8 \pi^{3} e^{4} \nu^{4} E^{2} N_{k}}{h^{2} c^{3}}\left|\sum_{n} A^{2}{ }_{k n}\left\{\frac{1}{\nu_{n k}-\nu}+\frac{1}{\nu_{n k}+\nu}\right\}\right|^{2}
$$

The corresponding expression for the scattering of modified wave length $\nu+\nu_{k l}$, from the same molecules due to the same illumination is

$$
S^{i}{ }_{k l}=\frac{8 \pi^{3} e^{4}}{h^{2} c^{3}} \nu^{4} E^{2} N_{k}\left|\sum_{n} A_{k n} A_{l n}\left\{\frac{1}{\nu_{n k}-\nu}+\frac{1}{\nu_{n l}+\nu}\right\}\right|^{2}
$$

In these expressions $E$ is the electric vector of the incident light. The subscripts $k, l$, and $n$ refer to various quantum states. The

3 Pringsheim and Rosen, Zeitschr. f. Phys., 50, p. 741; 1928. Wood, Phil. Mag., 6, p. 729; 1928. Bleeker, Zeitschr. f. Phys., 50, p. 781; 1928. Venkateswaran, Phil. Mag., 7, p. 597; 1929. No attempt is made in this paper to give a complete bibliography of the literature.

4 Dirac, Proc. Roy. Soc., A114, p. 710; 1927.

8 Kramers and Heisenberg, Zeitschr. f. Phys., 31, p. 681; 1925.

6 By considering the more general expression for any state of polarization one can see why some modified lines might be more completely polarized than the coherent scattered light. The effect is connected with the fact that all states, $k$, and all transitions $k \rightarrow n$ contribute to the unmodified scattering, while only particular transitions, $k \rightarrow n$ and $l \rightarrow n$ are involved in the scattering of a particular modified frequency, $\nu \pm \nu_{h l}$. 
quantities $A_{k n}$, for example, are the matrix elements of the moments corresponding to the transitions $k \rightarrow n$; that is

$$
A_{k n}=\int Z \psi_{k} \psi_{n} d \tau
$$

In such a transition there could be light absorbed or emitted of frequency $\nu_{k}-\nu_{n}=\nu_{k n}$, where $\nu_{k}$, for example, is the frequency in the state, $k$. If $l$ is above $k, \nu$ must be greater than $\nu_{l k}$. The sign of $\nu_{k n}$ determines whether it is an absorption or emission frequency.

One of the most important characteristics of expressions (1) and (2) is the first power dependance on the intensity, $E^{2}$, of the incident light, and on the number, $N_{k}$, of molecules (or atoms) in state $k$. Of course the theory underlying (1) and (2) involves the same restrictions which apply to the corresponding classical theory and therefore the limitations of the previous remark are similar. them

To make comparison between (1) and (2) easier we can rewrite

$$
\begin{gathered}
S^{c}{ }_{k}=\frac{8 \pi^{3} e^{4}}{h^{2} c^{3}} \nu^{4} E^{2} N_{k}\left|\sum_{n} \frac{2 A^{2}{ }_{k n} \nu_{n k}}{\nu^{2} n k}\right|^{2} \\
S_{k l}^{i}=\frac{8 \pi^{3} e^{4}}{h^{2} c^{3}} \nu^{4} E^{2} N_{k}\left|\sum_{n} \frac{A_{k n} A_{l n}\left(\nu_{n k}+\nu_{n l}\right)}{\left(\nu_{n k}-\nu\right)\left(\nu_{n l}+\nu\right)}\right|^{2}
\end{gathered}
$$

In the usual case, $\nu_{n l}-\nu_{n k}=\nu_{k l}$ is small compared with $\nu+\nu_{n k}\left(\nu_{k l}\right.$ is commonly less than $3,000 \mathrm{~cm}^{-1}$ ) and we may write as an approximation to (5).

$$
S_{k l}^{i}=\frac{8 \pi^{3} e^{4}}{h^{2} c^{3}} \nu^{4} E^{2} N_{k}\left|\sum_{n} \frac{A_{k n} A_{l n}\left(\nu_{n k}+\nu_{n l}\right)}{\nu^{2}{ }_{n k}-\nu^{2}}\left(1-\frac{\nu_{k l}}{\nu_{n k}+\nu}\right)\right|^{2}
$$

The sum $\nu_{k n}+\nu_{l n}$ is usually not very different from $2 \nu_{k n}$ so that the terms corresponding to any state, $n$, in the two expressions (4) and (6) will be approximately in the ratio $A_{k n}: \mathrm{A}_{l n}$. It is therefore possible that for some molecule or atom a particular modified frequency $\nu+\nu_{k l}$ might be scattered more strongly than the unmodified $\nu$. However, for incoherent scattering two conditions must be fulfilled simultaneously $\left(A_{k n} \neq 0, A_{l n} \neq 0\right)$ and then only certain combinations of states $k$ and $l$ will give a common modified frequency, while for coherent scattering only one $A_{k n}$ need differ from zero and all states, $k$, will give the same coherent scattered frequency $\nu$. It follows, therefore, that the coherent scattering will be much stronger in almost every case. This will appear very much the rule when one considers the way the values for the quantities, $A_{k n}$, run ordinarily and the states, $k$, which exist under ordinary conditions. However, the factor of several hundred or more by which the unmodified scattering usually exceeds the modified seems too large.

The dependence on the exciting wave length. brings out a related difficulty. According to (4) and (6) except for a very slowly varying term in (6) the two expressions contain $\nu$ in the same way and, therefore, the relative intensity should be independent of wave length. This is not quite true because the observed scattering comes from all possible states, $k$, and the values of $S^{i}{ }_{k} / S^{c}{ }_{k}$ as well as those of $\nu_{k n}$ will vary with $k$. However, in most cases actually encountered in scatter- 
ing experiments there is either only one important state, $k$, or else the $\nu_{k n}$ 's and the $A_{k n}$ 's are effectively the same for all values of $k$. And yet the intensity of the modified radiation seems to increase relative to that of the unmodified as one goes in the direction of increasing frequency.

The surprisingly large ratio $S^{c}{ }_{k} / S^{i}{ }_{k l}$, as well as its increase with wave length can, perhaps, be explained in part as being due to the nonlinearity of the characteristics of the photographic plates, but several experiments indicate this effect to be only a small one in most cases. It seems more plausible to attribute these anomalous effects to false reflections from the container walls or from foreign matter suspended in the scattering material. Such spurious scattering even though reduced with care might still enhance the intensity of the unmodified radiation manyfold and would, moreover, naturally be much weaker in the ultra-violet. It would, of course, not influence the modified scattering. The same cause might account in part for the fact that the polarization of unmodified radiation is never so complete as that of the modified. Another effect which certainly acts in some cases apparently to weaken the modified lines in the visible is the general fluorescence of the scattering substance or the container walls. Such fluorescence is uncommon in the ultra-violet and, moreover, being continuous is apparently reduced in intensity because of the increased dispersion of prism spectroscopes in the shorter wave lengths.

After this discussion of the relations between the properties of the coherent and the incoherent parts of the scattering we can profitably devote some attention to the special characteristics of the latter as described by (6). The frequencies, $\nu+\nu_{k l}$, whose intensities are given by (6) are either greater or less than $\nu$ depending on the sign of $\nu_{k l}$. For any frequency change, $\nu_{k l}$, there is in principle another of the opposite sign, $\nu_{l k}$, due to molecules in state $l$ because the expression for this frequency will be almost the same except for the factor $N_{l}$ instead of $N_{k}$ to represent the number of effective atoms. The relative intensities will, therefore, depend according to Boltzmann's law on the energy difference between the two states, $k$ and $l$. This factor relating to the number of atoms in the initial states does not entirely determine the intensity ratio between "Stokes" and "anti-Stokes" lines. The other factor becomes important when the exciting frequency, $\nu$, is close to $\nu_{n k}$ or $\nu_{n l}$ and a denominator in (2) or (6), therefore, becomes large. Of course this will not matter much unless the energy difference between states $k$ and $l$ is rather small, for otherwise the exponential factor will outweigh the effect of the small denominator. Depending on whether $\nu$ is close to $\nu_{n k}$ or $\nu_{n l}$ the "Stokes" or the "anti-Stokes" line may become more intense.

The case in which the exciting light is near an absorption line has not heretofore been of importance, but very probably the most interesting scattering experiments of the future will deal with such cases. When such zero denominators occur the scattered incoherent frequency coincides with some emission frequency which is therefore anomalously strong in coherent scattering. On this account it would be hard although by no means impossible to detect such strong incoherent scattering.?

7 It is worth mentioning that the frequencies of very strong atomic fluorescence are likely to have both coherent and incoherent components. 
Since the condition for scattering of frequency $\nu+\nu_{k l}$ is the nonvanishing of the two matrix elements $A_{k n}$ and $A_{l n}$ for some value of $n, \nu_{k l}$ is always the difference between two possible emission frequencies of the system; that is, $\nu_{k n}$ and $\nu_{l n}$ are such frequencies and $\nu_{k l}=\nu_{k n}-\nu_{l n}$. One of these, $\nu_{k n}$, must be an absorption frequency because the atoms are in state $k$, but $\nu_{l n}$ may not be observed in absorption if both $l$ and $n$ correspond to high energy states. Corresponding to any initial state, $k$, there may be many states, $l$, each of which will contribute a modified line. There may, moreover, be a number of states, $k$, which exist in sufficient concentration to serve as initial states.

The most characteristic feature of the scattering with change of frequency is that the magnitude of the frequency shift $\nu_{k l}$ is independent of the exciting frequency $\nu$. Data which show erratic values of $\nu_{k l}$ corresponding to different exciting lines must be inaccurate and we have found no such considerable variations.

The frequencies $\nu_{k l}$ need not be emission or absorption frequencies of the system. They may, of course, coincide with these and when practically all the systems are in the lowest level; that is, when the next level is so high that at the existing temperature the fraction of molecules having the necessary energy is negligible, the $\nu_{k l}$ will very likely also be absorption frequencies. In complicated molecules or in atoms with many optical electrons (high multiplicity in the lowest term), or in simple molecules because of selection rules the $\nu_{k l}$ are likely not to be observable as absorption lines. There are still other cases which could be deduced from (6) in which the $\nu_{k l}$ would be neither absorption frequencies nor emission lines.

An interesting question to decide is the location of the levels, $n$, which are important in contributing to a modified line. Of course the primary requisite is that the denominators $A_{k n} A_{l n}$ must be appreciable. Usually only a few states, $n$, will satisfy this condition or if there are many they will be fairly close in energy and there will be either a single or a narrow range of important values of $\nu_{k n}$. Of course the important $\nu_{k n}$ may change, depending on the frequency of exciting light because different denominators may then become small, but all these cases can be discussed sufficiently well by considering that there is only one state, $n$, which combines both with $k$ and with $l$. The state $n$ may belong to the same electronic level as $k$ and $l$ so that $\nu_{k n}$ will be an infra-red frequency usually or it may belong to another electronic level, in which case $\nu_{k n}$ would most likely be in the ultra-violet. The transition probabilities are likely to be larger for the transitions involving electronic changes and on that account states $n$ in the same electronic level will be unimportant. In addition, the term $\nu_{n k}+\nu_{n l}$ in the numerator of (6) is comparatively very small for these states. Finally, since the exciting light is always visible or ultra-violet, it is never close to $\nu_{k n}$ so that there is no chance for a very small denominator. It seems, therefore, safe to conclude that the transitions $n \rightarrow k$ and $n \rightarrow l$ which play a part in the incoherent scattering are electronic transitions involving large energies. For very large energy changes, however, the value of (6) again becomes small and varies as $\nu_{n k}{ }^{-2}$ so that even if $A_{k n} A_{l n}$ were large for such transitions they might make little contribution to the scattering.

The dependence of the incoherent scattering on wave length of incident light is, as has already been mentioned, very nearly the same 
as in the case of coherent scattering. Certain differences and special features might well be emphasized. The first is the restriction that if $\nu_{k l}$ is negative, $\nu$ must be greater than $\nu_{l k}$. This condition is almost always satisfied because the $\nu_{k l}$ are infra-red frequencies while $\nu$ is visible or ultra-violet. Of greater practical significance is the fourth power increase of (6) with frequency and the additional increase as $\nu$ approaches an absorption frequency $\nu_{n k}$. If $\nu$ is less than $\nu_{n k}$ the combined effect of these two factors is to make $S^{i}{ }_{k l}$ increase faster than the fourth power of $\nu$. After $\nu$ exceeds $\nu_{n k}$, the scattering first decreases as $\nu$ increases, then tends to become constant in the limit when $\nu / \nu_{n k} \gg 1$. The ordinary case is $\nu_{n k}>\nu$ so that we expect to find a very rapid increase of scattering coefficient with $\nu$. If, however, $\nu_{n k}$ is an infra-red frequency we should find little or no increase of intensity in going toward the ultra-violet. An approximate expression for all these cases can be written

$$
S_{k l}^{i} \approx S_{0}\left(1-\frac{\nu_{n k}^{2}}{\nu^{2}}\right)^{-2}
$$

\section{EXPERIMENTAL}

Every element of volume subject to illumination scatters according to (4) and (6) a certain fraction of the incident energy. It is therefore desirable in investigating the scattering to use as bright a source as possible and illuminate as much as possible of the useful space available, namely, the space included in the aperture of the spectrograph. It is important to have the boundaries of the scattering substance outside the spectrograph aperture at least in the portions subjected to bright illumination because these boundaries at which there is a change of refractive index have a reflection coefficient which usually is enormously larger than the scattering coefficient of the transparent homogeneous substance under investigation.

The natural arrangement of apparatus from the point of view of the previous paragraph is a cylindrical vessel containing the scattering substance on the axis of the spectrograph and a cylindrical light source placed parallel to the scattering tube and as close to it as convenient. A source concentric with the scatterer would also be desirable, and it was tried in the present work. It gave good results after a cooling system was worked out, but it broke before much was accomplished. Somewhat the same effect can be attained by using reflectors all around the source and scattering tube.

Practically all of the data given in this paper were obtained with a special arc designed to satisfy the requirements of high intensity, proper size and shape, and ease of construction and operation. The source referred to is a mercury arc, operated in a quartz capillary open to the atmosphere. Figure 1 is an example of a very convenient shape of such an arc showing the essential features of design. The capillary which was most used had a bore of $2 \mathrm{~mm}$ and a length of about $7.5 \mathrm{~cm}$. At the top and bottom of this length the tube widened rather suddenly so that there was an abrupt increase of conductivity and heat capacity. This limited the arc to the capillary part, because outside of this the heat could be dissipated rapidly enough to keep the temperature below boiling. The arc was started by heating the capillary part until a vapor space formed. Then a switch was closed 
so that when the vapor condensed a circuit was closed, an arc was struck, and the lamp was plunged under water. The applied potential was 220 volts and a heavy rheostat in series limited the current to about 10 amperes. The arc quickly forces the liquid back to the wider portions and if the resistance is suitable will burn there, taking a current of about 3 amperes with a potential drop of somewhat over 100 volts across the arc.

If no further precautions are taken, the arc is sure to hammer because of its instability. This renders the arc practically useless

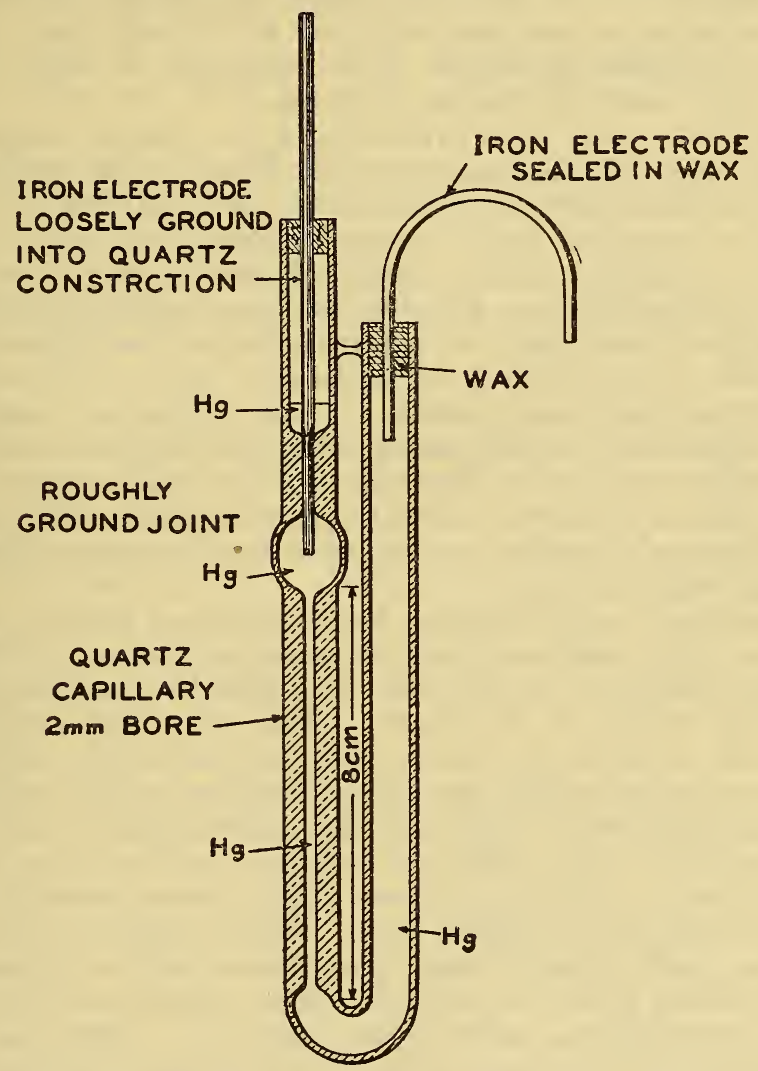

FIgURE 1.-Quartz mercury arc used in the investigation of light scattering in liquids

and, moreover, is very likely to break the quartz tubing. To overcome it, one electrode is waxed in while the other fits fairly snugly in a constriction, thus damping any flow of mercury. This fit can be accomplished by grinding in the iron rod over a width of a few millimeters. If the grinding is too good, flow would be stopped completely and the arc would soon go out. It is very important that the iron rod project well into the widened part of the quartz tube. Otherwise a bubble forming in the constriction might either break the circuit or else arc across with high probability of breaking the arc, in any case putting it out. 
The mercury must be well boiled out of the capillary to eliminate occluded gas and water, and should be clean and pure. In the best of cases it soon darkens the inside of the capillary which is then impossible to clean satisfactorily. The initial brilliancy rapidly diminishes during the first half hour and after 20 hours there is a brown discoloration (devitrified quartz or silicon) inside and a white coat (salts from the water) outside. This white coat can be scraped off moderately well. The life of such arcs may be over 100 hours, but on account of gradual discoloration in the capillary their efficiency is greatly reduced after 20 or 30 hours' operation. When old the capillary can be sawn out and replaced by a fresh piece. Working under the conditions described it is necessary to cool the arc in running water immediately after it strikes.

These arcs have very high brilliancy in the visible and near ultraviolet (down to $3126 \mathrm{~A}$ ) and the strong lines in this region are not very broad so that they are satisfactory for scattering in liquids at least, since the modified lines themselves appear to have a comparatively large intrinsic width. Some of the strong mercury lines $(3125,3131,3650,4358)$ are narrowly reversed under high dispersion. Farther in the ultra-violet the intensity is not very great and the lines are often very diffuse. In particular, $2537 \mathrm{~A}$ is so wide and strongly reversed that it is useless for our purposes. Besides being extremely bright and easy to make, these arcs are most compact and can be brought very close to the tube which it is desired to illuminate. The most obvious disadvantage is the continuous background which while comparatively weak is nevertheless much brighter than that of the ordinary vacuum arc.

The theoretical considerations have indicated that it would be desirable to work with as short a wave length as possible. The limitation is usually set in the case of liquids by the absorption and photochemical action in the liquid. For most organic substances this limit is above $3000 \mathrm{~A}$; that is, in the region where high-pressure mercury arcs are especially strong. The filter used to cut out the farther ultra-violet was merely the thin pyrex glass of the container of the scattering liquid. This was very transparent down to $3300 \mathrm{~A}$ and satisfactory to $3100 \mathrm{~A}$. Even $2967 \mathrm{~A}$ was recorded by long exposures and showed modified lines. In the cases of $\mathrm{CCl}_{4}, \mathrm{CHCl}_{3}$, $\mathrm{C}_{6} \mathrm{H}_{6}, \mathrm{C}_{6} \mathrm{H}_{14}, \mathrm{C}_{6} \mathrm{H}_{12}$ (cyclohexane) the photochemical action of the pyrex transmitted light was negligibly slow. On the whole, the pure saturated hydrocarbons were little affected. Water and $\mathrm{H}_{2} \mathrm{SO}_{4}$, quartz and calcite showed no action. But in very complicated molecules, highly unsaturated or loaded with halogens, a rapid change takes place. Often it is impossible to get a single exposure before the liquid is ruined by discoloration, by coagulation, by gas formation or fluorescence or by formation of finely divided suspensions. In many instances, no doubt, impurities were the cause of the nuisance. One of the most flagrant cases was the formation of a yellow-brown mass in $\mathrm{CS}_{2}$ after a few minutes exposure through glass. Even when exposure was made through $2 \mathrm{~cm}$ of heavy flint glass this liquid would become yellow in half an hour.

With the unshielded arc and quartz tubes almost everything quickly decomposed. Only $\mathrm{H}_{2} \mathrm{O}$ and $\mathrm{H}_{2} \mathrm{SO}_{4}$ seemed to resist. Ethyl alcohol bubbled somewhat, while $\mathrm{CH}_{3} \mathrm{OH}$ went much faster. Higher alcohols were less stable and more disagreeable. Ammonia water 
gave off $\mathrm{NH}_{3}$, and acetic acid bubbled. Nitrates turned yellow and became more or less opaque. Nitrites behaved better, but also absorbed strongly. $\mathrm{CCl}_{4}$ discolored rapidly and $\mathrm{C}_{6} \mathrm{H}_{6}$ immediately gave a brown film to the walls which was hard to remove. It should be mentioned that purer benzene formed the brown solid more slowly.

As was already pointed out, the scattering in the visible was marred by reflection of suspended matter and continuous fluorescence of the scatterer or some impurity in it. To cut this down the purest available liquids were sealed in a viewing tube which had a reservoir attached. The liquid was evaporated at as low a temperature as convenient (usually $50^{\circ}$ to $70^{\circ}$ C.) and then poured back into the reservoir. After a few repetitions of this process they were considerably improved and ready for use in the light-scattering experiments.

The viewing tubes were about $2 \mathrm{~cm}$ in diameter and cylindrical for a length of about 12 to $15 \mathrm{~cm}$. Then they tapered down to about $6 \mathrm{~mm}$ and bent over to the reservoir. The top part was blackened and formed a good light trap. The bottom was blown out thin and round. Since the whole was immersed in water there was not enough difference in refractive index on the two sides of the glass to give much lens effect so that these were as good as flat ends for liquids. The tube was held in the axis of a water cooler so that it could be lifted out and replaced without requiring realignment. A lens focused a point well inside the tube and on its axis, onto the slit of a spectrograph. This was horizontal so that a totally reflecting quartz prism was used near the slit to send the vertical scattered beam into the spectrograph. The advantage of having the scattering tube some distance from the slit and using a lens of about the same aperture ratio as that of the spectrograph was to cut down the wide angle reflection of stray light on the spectrograph slit which would fog the plate on long exposures.

The cooling chamber was arranged so that several arcs could be inserted close by the scattering tube. Usually one or two were used and then with substances like $\mathrm{C}_{6} \mathrm{H}_{6}, \mathrm{CHCl}_{3}$, and $\mathrm{CCl}_{4}$ good exposures could be obtained with the Hilger E2 quartz spectrograph in several minutes. The exposures which were used for measurements were, however, run from 15 minutes up to two hours in order to observe the weaker lines. The modified lines of greatest intensity could be photographed in a second with the E2 spectrograph when the slit width was $0.02 \mathrm{~mm}$. Illuminating with three arcs the stronger lines characteristic of scattering liquids were photographed with a 21-foot concave grating by exposing from two to five hours.

Most of the plates which were measured were exposed in a Hilger E2 quartz spectrograph giving a dispersion of $14 \mathrm{~A} / \mathrm{mm}$ at $3000 \mathrm{~A}$, $36 \mathrm{~A} / \mathrm{mm}$ at $4000 \mathrm{~A}$, and $69 \mathrm{~A} / \mathrm{mm}$ at $5000 \mathrm{~A}$. The grating spectrograms had a uniform scale of $10.4 \mathrm{~A} / \mathrm{mm}$ when the Anderson grating with 7,500 lines per inch was used in the parallel light mounting described in other publications. ${ }^{8}$ A new grating ruled by Professor Wood with 15,000 lines per inch was also used in the same mounting. It gave a scale of $5.3 \mathrm{~A} / \mathrm{mm}$ in the first-order spectrum, and although it concentrated much of the light in this spectrum it was still somewhat less efficient than the Anderson grating and required exposures of 5 to 20 hours.

Meggers and Burns, B, S. Sci. Papers (441), 18, p. 191; 1922. 
Many preliminary exposures were made, especially with the quartz spectrograph, to study qualitatively the nature of the scattered light and to develop the best technique for systematic observations. Several different brands of high-speed photographic plates were tried, and panchromatic emulsions were also used. The plates which have the highest $H \& D$ speeds for white light are objectionable for spectrographic work on account of their coarse grain and low resolving power. Panchromatic emulsions are of little value in connection with quartz spectrographs because of the relatively small dispersion which quartz gives in the region of longer. wave lengths (112 A/mm at $6000 \mathrm{~A})$. Although we have measured some wave lengths of modified lines greater than $6500 \mathrm{~A}$, the precision of measurement is not comparable with that obtained below $5000 \mathrm{~A}$. We finally decided to use only the finer grained color-blind plates, such as Seed's 23. For spectrographic work in the violet and adjacent ultra-violet these appear to be no slower than the so-called highspeed plates, and they have a decided advantage in definition. Our observations have, therefore, been restricted for the most part to the spectral interval between 3000 and $5000 \mathrm{~A}$, the lower limit being set by the absorption in pyrex glass and the upper one by the insensitiveness of ordinary photographic emulsions to longer waves.

Our preliminary exposures were made without comparison spectra, and approximate values for the wave lengths of modified lines were obtained by interpolation between the published values of mercury lines. This is the procedure followed by most of the workers who have published data in this field, and it accounts in a large measure for the qualitative and discordant results. It is entirely inadequate for precision measurements because most of the unmodified mercury lines used as standards are enormously overexposed in spectrograms of scattered radiation and there are, moreover, many intervals of several hundred angstrom units where no suitable standards are available. Furthermore, attention may be called to the fact that in spite of the multitude of investigations to which the mercury spectrum has been subjected no complete and accurate description of the spectrum is available. Remarkable differences occur between the spectrum of the vacuum mercury arc and the arc in air, but neither source can claim a satisfactory list of wave lengths nor relative intensities of the lines. Incidental to our investigation of light scattering in liquids we have made a new description of the spectrum of the atmospheric-pressure mercury arc used in these experiments. The wave lengths were measured on grating spectrograms made with the Wood grating referred to above; they are based on the international secondary standards in the iron arc spectrum which was superposed on the exposure to the mercury arc. Many of the lines in this type of mercury arc are hazy, wide, and unsymmetrical, and it is not possible to define the wave lengths of such lines closer than about $0.1 \mathrm{~A}$. The remaining lines are sharper and can be specified to $0.01 \mathrm{~A}$. The new data served to identify the mercury lines measured in our spectra of light scattered by liquids, and the wave numbers of the stronger lines were referred to in calculating the shifts of modified lines, but no use of the mercury lines has been made as wave-length standards.

A comparison spectrum was placed on every spectrogram of scattered light used for wave-length determinations, a copper arc being employed with the prism spectrograph and an iron arc with the 
grating spectrograph. All the lines on each of the spectrograms of scattered radiation were measured and reduced to wave lengths by interpolation between measured standards-viz, Hasbach's ${ }^{9}$ values for copper arc lines and the international values ${ }^{10}$ for iron arc lines. All spectrograms were measured in two directions. Wave-length data were derived from the prismatic spectrograms by means of the Hartmann interpolation formula ${ }^{11}$ and from grating spectrograms by linear interpolation, corrections indicated by adjacent standards being applied in either case.

Each wave length was determined from at least five or six plates and the probable error of the average was computed. The probable error for the sharper lines is usually less than $0.05 \mathrm{~A}$, but since most of the modified lines in scattered light are intrinsically wide and hazy, we have rounded off our wave length to the nearest $0.1 \mathrm{~A}$. On account of the relatively low dispersion and resolving power of the E2 quartz spectrograph in the interval 3000 to $5000 \mathrm{~A}$, we believe that this is about the limit of precision obtainable with this instrument. With more powerful spectrographs it should be possible to define the sharper lines with greater accuracy, and we have attempted to do this by giving our grating measurements of modified lines to two decimal places. One of the sharpest and strongest lines which various investigators have observed in the spectrum of mercury light scattered by liquids is the line $4555 \mathrm{~A}$ emitted by benzene when excited by the blue line of mercury, $4358 \mathrm{~A}$. The various values obtained for this line by different observers are as follows:

Raman and Krishan ${ }^{12}$

Wood ${ }^{13}$ 4555. 8

Pringsheim and Rosen ${ }^{14}$

Wood ${ }^{15} \ldots$

Langer and Meggers (prism)

Langer and Meggers (grating)

The agreement between different observers is, in general, not so good for the other lines, and the frequency shifts reported for benzene (and other substances) often differ by as much as 2 per cent, not to mention imaginary lines or misinterpreted lines which lead to false frequency shifts.

In the interval 3000 to $5000 \mathrm{~A}$ with an unfiltered mercury arc there are present about 10 or 12 mercury lines with sufficient intensity to give modified scattering for all but the weakest frequency shifts. The identification of a frequency shift is definite; connection of modified lines with the exciting lines is unambiguous, and increased precision may be expected by averaging the values from the different pairs of related lines. Occasionally a modified line will fall upon or close to another mercury line, but this loss is more than compensated for by the possibility of observing the same shift ten to twenty times on each spectrogram.

In agreement with expectations from theory the frequency shifts from different lines are consistent not only in numerical value, but in general appearance and intensity of the modified lines. In our observations the average deviation of individual shifts from the

${ }^{9}$ Hasbach, Zeitschr., f. wiss. Phot., 13, p. 399; 1914.

10 Trans. I. A. U., in, p. 86; 1928. Kayser and Konen, Handbuch der Spectroscopie VI, p. $423 ; 1924$.

11 Meggers, Dictionary of Applied Physics, IV, p. 890; 1923.

12 Raman and Krishan, Indian J. Phys., 2, p. 399; 1928.

13 Wood, Phil. Mag., 6, p. 729; 1928.

14 Pringsheim and Rosen, Zeitschr. f. Phys., 56, p. 741; 1928.

is Wood, Phil. Mag., 6, p. 1282; 1928 . 
average value of a particular displacement is about 0.6 of a wave number unit. This is an indication that the average probable error in the wave length of a modified line is less than $0.1 \mathrm{~A}$. An error of $0.1 \mathrm{~A}$ entails an error of 1.1 wave number at $3100 \mathrm{~A}, 0.6$ wave number at $4000 \mathrm{~A}$, and 0.4 wave number at $5000 \mathrm{~A}$.

Systematic errors are not easy to avoid in spectrographic work involving relatively long exposures, wave-length measurements from curved images characteristic of prism spectrographs, and a comparison of data obtained from different instruments. It is, perhaps, conceivable that the measurements on "Stokes" and "anti-Stokes" lines would reveal systematic errors if any are present, since the displacements in both directions are expected to be equal. When this test is applied to our measurements on carbon tetrachloride, it yields for the shift 459.3 a value of 458.6 for "Stokes" lines and -460.1 for "anti-Stokes," while for the 313.9 shift it shows 313.8 for "Stokes" and -314.0 for "anti-Stokes." Similarly the measurements on chloroform averaging 365.8 show an average of 365.5 for "Stokes" and -366.0 for "anti-Stokes" lines. There appears thus to be a slight tendency for the negative shifts to exceed the positive; this can be explained as a systematic error of about $-0.1 \mathrm{~A}$ in the modified lines. This is the type of error which may be expected in measurements of prismatic spectrograms if the comparison spectrum is placed in the center and no correction is made for the curvature of the slit images. It must be remembered, too, that the "anti-Stokes" lines are always fainter than the "Stokes" lines and the difference in shifts may indicate an intensity equation. Fortunately the discrepancy appears to be no larger than the average probable error.

Attention is called to the remarkable differences between various liquids as regards the production of "Stokes" and "anti-Stokes" lines. Although bright "Stokes" lines of about the same intensity are found in spectra of light scattered by benzene, toluene, chloroform, and carbon tetrachloride, "anti-Stokes" lines were almost entirely absent in the first two but very prominent in the last two. The intensity ratio S/aS ("Stokes"/"anti-Stokes") increases rapidly with increasing displacement from the exciting line; comparison of our intensity estimates in the case of carbon tetrachloride show surprising agreement with the quantitative measurements of Ornstein and Rekveld. ${ }^{16}$ In our experiments the temperature of the liquid was about $45^{\circ} \mathrm{C}$. or $318^{\circ} \mathrm{K}$. Under these conditions the ratios of estimated intensities for lines excited by $4358 \mathrm{~A}$ and corresponding to the first three shifts $\left(\nu_{1}=219, \nu_{2}=314, \nu_{3}=459\right)$ characteristic of carbon tetrachloride are as follows:

$$
I_{s} / I_{a s}=2.5 \text { for } \nu_{1} ; 4.0 \text { for } \nu_{2} \text {; and } 8.0 \text { for } \nu_{3}
$$

With carbon tetrachloride at $323.5^{\circ} \mathrm{K}$., Ornstein and Rekveld determined these ratios to be $2.5,3.9$, and 8.1 , respectively, while the theoretical values are $2.55,3.95$, and 7.4. The close agreement may be accidental, since we can lay no claim to quantitative results based on arbitrary estimations of relative intensities, but it is reassuring to observe that our estimates are fairly consistent; the average value of the intensity ratios for six or seven different exciting lines being 2.5, 3.8 , and 7.5 .

${ }^{16}$ Ornstein and Rekveld, Phys. Revi., 34, p. 720; 1929. 
According to our intensity estimates for modified lines from chloroform the corresponding intensity ratios $I_{s} / I_{a_{3}}$ are 2.5, 5.0, and 10.0 for the three shifts 261,366 , and 668 , respectively.

\section{RESULTS}

Details of the numerical data are collected in this section beginning with Table 1, which is a description of the spectrum of the mercury arc operated at atmospheric pressure. Wave lengths are given in the first column, estimated relative intensities in the second, and vacuum wave numbers in the third. The letters accompanying intensities have the following significance: $\mathrm{h}=\mathrm{hazy}, \mathrm{H}=$ very hazy and wide, $\mathrm{d}=$ double, $\mathrm{R}=$ reversed, $\mathrm{v}=$ shaded to violet, $\mathrm{l}=$ shaded to red. Practically all of these lines appeared on each of the prismatic spectrograms, but by comparing the complete lists of wave lengths with each other and with Table 1 it was possible to identify all the unmodified mercury lines and separate them from the modified wave lengths. Besides serving for the identification and elimination of mercury lines the data of Table 1 are referred to for the determination of wave number displacements characterizing the modified lines. Two mercury lines at 3125 and $3131 \mathrm{~A}$, forming a pair of roughly the same intensity, are especially useful in the identification of displacements, since they give corresponding to each shift a pair of modified lines which are recognizable at a glance. Owing to the increase in intensity of modified lines with increasing frequency of the exciting line these ultra-violet lines (3125 and $3131 \mathrm{~A}$ ), although less than onetenth as strong as the blue line, $4358 \mathrm{~A}$, nevertheless give modified lines of intensity comparable with those from the latter. The only objection which can be raised against this ultra-violet pair is that the longer wave length line is double. The two components are separated by $0.3 \mathrm{~A}$ and appear to be about the same intensity. Since this close pair is not resolved in ordinary prism spectrographs we have used the unweighted mean of the two lines as the effective value for the exciting line. The two lines, 3125 and $3131 \mathrm{~A}$, then appear to be separated by 62.0 wave number units, while the mean separation of 35 pairs of modified lines arising from this pair is 61.8 wave number units. This small difference could be compensated for by giving the shorter wave component of $3131 \mathrm{~A}$ slightly larger weight so that the effective wave length of the line would be diminished by $0.02 \mathrm{~A}$.

Tables 2, 3, 4, and 5 present the observed data on modified lines scattered by benzene, toluene, chloroform, and carbon tetrachloride, respectively. ${ }^{17}$ The measured wave lengths appear in the first column of each, the estimated relative intensities in the second, the corresponding vacuum wave number in the third, the vacuum wave numbers of the parent, exciting mercury lines in the fourth, and the shifts in the last. A minus sign before the shift number indicates an "anti-Stokes" line shifted to violet; all of the remaining shifts are toward longer wave lengths. Wave lengths expressed to two decimal places are derived from grating spectrograms; the remainder are based on measurements of smaller scale prism spectrograms. On account of the relatively large intrinsic width and generally diffuse or unsymmetrical character of most of the modified lines it is doubtful

${ }_{17}$ We are pleased to acknowledge the assistance of Bourdon Scribner with wave-length calculations, and of John A. Wheeler, who measured and reduced several spectrograms of toluene. 
if a second decimal place has much significance but it is retained here to distinguish grating from prism observations.

TABLE 1.-Spectrum of the mercury arc at atmospheric pressure

\begin{tabular}{|c|c|c|c|c|c|c|c|c|}
\hline$\lambda$ & Intensity & $\nu_{\nabla \mathbf{a c}}$ & $\lambda$ & Intensity & $\nu_{\text {vac. }}$ & $\lambda$ & Intensity & $\nu_{\mathrm{vac}}$ \\
\hline $\begin{array}{l}2,967.20 \\
3,006.97 \\
3,011.13 \\
3,021.57 \\
3,023.59\end{array}$ & $\begin{array}{l}100 \\
5 \mathrm{hv} \\
2 \mathrm{H} \\
200 \mathrm{~h} \\
30 \mathrm{~h}\end{array}$ & $\begin{array}{l}33,692.0 \\
33,246.4 \\
33,200.5 \\
33,085.8 \\
33,063.7\end{array}$ & $\begin{array}{l}3,579.1 \\
3,597.45 \\
3,615.2 \\
3,650.15 \\
3,654.77\end{array}$ & $\begin{array}{l}2 \mathrm{H} \\
2 \mathrm{~h} \\
3 \mathrm{H} \\
5,000 \mathrm{R} \\
1,000\end{array}$ & $\begin{array}{l}27,932 \\
27,789.6 \\
27,653 \\
27,388.4 \\
27,353.7\end{array}$ & $\begin{array}{l}3,906.8 \\
3,983.97 \\
4,024.14 \\
4,046.63 \\
4,077.90\end{array}$ & $\begin{array}{c}100 \mathrm{H} 1 \\
40 \\
2 \\
4,000 \\
400\end{array}$ & $\begin{array}{l}25,589 \\
25,093.5 \\
24,843.0 \\
24,705.0 \\
24,515.5\end{array}$ \\
\hline $\begin{array}{l}3,027.56 \\
3,038.52 \\
3,050.2 \\
3,125.56 \\
3,131.63\end{array}$ & $\begin{array}{c}5 \mathrm{~h} \\
2 \\
1 \mathrm{Hl} \\
600 \mathrm{R} \\
800 \mathrm{Rd}\end{array}$ & $\begin{array}{l}33,020.3 \\
32,901.2 \\
32,775 \\
31,985.0 \\
31,923.0\end{array}$ & $\begin{array}{l}3,662.92 \\
3,663.25 \\
3,680.48 \\
3,751.74 \\
3,755.19\end{array}$ & $\begin{array}{l}100 \\
500 \\
40 \mathrm{~h} \\
60 \mathrm{~h} \\
7 \mathrm{~h}\end{array}$ & $\begin{array}{l}27,292.9 \\
27,290.4 \\
27,162.7 \\
26,646.8 \\
26,622.3\end{array}$ & $\begin{array}{l}4,108.5 \\
4,140.4 \\
4,314.0 \\
4,339.46 \\
4,347.66\end{array}$ & $\begin{array}{c}100 \mathrm{Hl} \\
1 \mathrm{H} \\
10 \mathrm{HV} \\
300 \mathrm{~h} \\
600 \mathrm{~h}\end{array}$ & $\begin{array}{l}24,333 \\
24,145 \\
23,174 \\
23,037.9 \\
22,994.4\end{array}$ \\
\hline $\begin{array}{l}3,144.40 \\
3,341.57 \\
3,351.51 \\
3,366.7 \\
3,390.66\end{array}$ & $\begin{array}{c}4 \\
200 \\
10 \\
2 \mathrm{H} \\
30 \mathrm{~h}\end{array}$ & $\begin{array}{l}31,793.4 \\
29,917.5 \\
29,828.8 \\
29,694 \\
29,484.3\end{array}$ & $\begin{array}{l}3,770.9 \\
3,790.0 \\
3,801.5 \\
3,807.8 \\
3,820.3\end{array}$ & $\begin{array}{r}30 \mathrm{Hl} \\
150 \mathrm{Hl} \\
5 \mathrm{H} \\
3 \mathrm{H} \\
80 \mathrm{H}\end{array}$ & $\begin{array}{l}26,511 \\
26,378 \\
26,298 \\
26,254 \\
26,169\end{array}$ & $\begin{array}{l}4,358.38 \\
4,916.38 \\
4,960.26 \\
5,025.84 \\
5,046.2\end{array}$ & $\begin{array}{r}10,000 \mathrm{r} \\
800 \mathrm{~h} \\
600 \mathrm{~h} \\
5 \mathrm{~h} \\
5 \mathrm{H}\end{array}$ & $\begin{array}{l}22,937.9 \\
20,334.5 \\
20,154.6 \\
19,891.6 \\
19,811\end{array}$ \\
\hline $\begin{array}{l}3,430.6 \\
3,433.65 \\
3,543.41 \\
3,561.18 \\
3,561.84\end{array}$ & $\begin{array}{c}4 \mathrm{H} \\
1 \\
60 \mathrm{H} \\
20 \mathrm{~h} \\
4 \mathrm{~h}\end{array}$ & $\begin{array}{l}29,141 \\
29,115.2 \\
28,213.4 \\
28,072.6 \\
28,067.4\end{array}$ & $\begin{array}{l}3,829.9 \\
3,842.4 \\
3,860.8 \\
3,894.3 \\
3,902.4\end{array}$ & $\begin{array}{l}1 \mathrm{H} \\
1 \mathrm{H} \\
50 \mathrm{H} \\
4 \mathrm{H} d(?) \\
3 \mathrm{H}\end{array}$ & $\begin{array}{l}26,103 \\
26,018 \\
25,894 \\
25,671 \\
25,618\end{array}$ & & 7 & \\
\hline
\end{tabular}

TABLE 2.-Modified $\mathrm{Hg}$ lines scattered by benzene $\left(\mathrm{C}_{6} \mathrm{H}_{6}\right)$

\begin{tabular}{|c|c|c|c|c|c|c|c|c|c|}
\hline$\lambda$ & $\begin{array}{l}\text { Inten- } \\
\text { sity }\end{array}$ & $\begin{array}{c}\nu_{\text {Vac }} \\
\text { modified } \\
\text { line }\end{array}$ & $\begin{array}{c}\nu_{\text {rac }} \\
\text { exciting } \\
\text { line }\end{array}$ & Shift & $\lambda$ & $\begin{array}{c}\text { Inten- } \\
\text { sity }\end{array}$ & $\begin{array}{c}\nu_{\mathrm{vac}} \\
\text { modified } \\
\text { line }\end{array}$ & $\begin{array}{c}\nu_{\mathrm{Vac}} \\
\text { exciting } \\
\text { line }\end{array}$ & Shift \\
\hline $\begin{array}{l}3,057.3 \\
3,077.8 \\
3,083.4 \\
3,085.8 \\
3,089.3\end{array}$ & $\begin{array}{l}5 \\
1 \\
1 \\
2 \\
1\end{array}$ & $\begin{array}{l}32,699.1 \\
32,481.3 \\
32,422.3 \\
32,397.1 \\
32,360.4\end{array}$ & $33,692.0$ & 992.9 & $\begin{array}{l}3,706.5 \\
3,722.2 \\
3,732.5 \\
3,737.6 \\
3,746.2\end{array}$ & $\begin{array}{l}2 \mathrm{H} \\
7 \mathrm{~h} \\
6 \mathrm{~h} \\
2 \mathrm{~h} \\
2\end{array}$ & $\begin{array}{l}26,972.0 \\
26,858.2 \\
26,784.1 \\
26,747.6 \\
26,686.2\end{array}$ & $\begin{array}{l}29,917.5 \\
29,917.5 \\
27,388.4 \\
27,353.7 \\
27,290.4\end{array}$ & $\begin{array}{r}2,945.5 \\
3,059.3 \\
604.3 \\
606.1 \\
604.2\end{array}$ \\
\hline $\begin{array}{l}3,114.9 \\
3,185.9 \\
3,192.3 \\
3,210.7 \\
3,217.2\end{array}$ & $\begin{array}{l}5 \mathrm{~h} \\
4 \mathrm{~h} \\
5 \mathrm{~h} \\
3 \mathrm{~h} \\
4 \mathrm{~h}\end{array}$ & $\begin{array}{l}32,094.5 \\
31,379.3 \\
31,316.4 \\
31,136.9 \\
31,074.0\end{array}$ & $\begin{array}{l}33,085.8 \\
31,985.0 \\
31,923.0 \\
31,985.0 \\
31,923.0\end{array}$ & $\begin{array}{l}991.3 \\
605.7 \\
606.6 \\
848.1 \\
849.0\end{array}$ & $\begin{array}{l}3,766.4 \\
3,787.21 \\
3,792.21 \\
3,801.30 \\
3,814.0\end{array}$ & $\begin{array}{r}2 \mathrm{~h} \\
30 \mathrm{~h} \\
15 \mathrm{~h} \\
10 \mathrm{~h} \\
3 \mathrm{~h}\end{array}$ & $\begin{array}{l}26,543.0 \\
26,397.2 \\
26,362.4 \\
26,299.3 \\
26,211.8\end{array}$ & $\begin{array}{l}27,388.4 \\
27,388.4 \\
27,353.7 \\
27,290.4 \\
27,388.4\end{array}$ & $\begin{array}{r}845.4 \\
991.2 \\
991.3 \\
991.1 \\
1,176.6\end{array}$ \\
\hline $\begin{array}{l}3,225.7 \\
3,232.1 \\
3.244 .8 \\
3,251.4 \\
3,263.7\end{array}$ & $\begin{array}{r}20 \mathrm{~h} \\
25 \mathrm{~h} \\
4 \mathrm{~h} \\
5 \mathrm{~h} \\
6 \mathrm{~V}\end{array}$ & $\begin{array}{l}30,992.1 \\
30,930.7 \\
30,809.7 \\
30,747.1 \\
30,631.3\end{array}$ & $\begin{array}{l}31,985.0 \\
31,923.0 \\
31,985.0 \\
31,923.0 \\
33,692.0\end{array}$ & $\begin{array}{r}992.9 \\
992.3 \\
1,175.3 \\
1,175.9 \\
3,060.7\end{array}$ & $\begin{array}{l}3,828.4 \\
3,874.4 \\
3,879.6 \\
3,889.4 \\
4,008.6\end{array}$ & $\begin{array}{l}2 \mathrm{~h} \\
6 \mathrm{~h} \\
4 \mathrm{~h} \\
2 \mathrm{~h} \\
1 \mathrm{~h}\end{array}$ & $\begin{array}{l}25,113.2 \\
25,803.2 \\
25,768.6 \\
25,703.6 \\
24,939.3\end{array}$ & $\begin{array}{l}27,290.4 \\
27,388.4 \\
27,353.7 \\
27,290.4\end{array}$ & $\begin{array}{l}1,177.2 \\
1,585.2 \\
1,585.1 \\
1,586.8\end{array}$ \\
\hline $\begin{array}{l}3,288.4 \\
3,290.6 \\
3,295.3 \\
3,297.5 \\
3,329.4\end{array}$ & $\begin{array}{l}3 \mathrm{~h} \\
2 \mathrm{~h} \\
3 \mathrm{~h} \\
2 \mathrm{~h} \\
4 \mathrm{~h}\end{array}$ & $\begin{array}{l}30,401.2 \\
30,380.9 \\
30,337.5 \\
30,317.3 \\
30,026.8\end{array}$ & $\begin{array}{l}31,985.0 \\
31,985.0 \\
31,923.0 \\
31,923.0 \\
33,085.8\end{array}$ & $\begin{array}{l}1,583.8 \\
1,604.1 \\
1,585.5 \\
1,605.7 \\
3,059.0\end{array}$ & $\begin{array}{l}4,090.1 \\
4,115.27 \\
4,125.92 \\
4,148.2 \\
4,190.7\end{array}$ & $\begin{array}{c}3 \mathrm{~h} \\
10 \\
20 \\
5 \\
2\end{array}$ & $\begin{array}{l}24.442 .4 \\
24,292.9 \\
24,230.2 \\
24,100.1 \\
23,855.7\end{array}$ & $\begin{array}{l}27,388.4 \\
27,353.7 \\
27,290.4 \\
24,705.0 \\
24,705.0\end{array}$ & $\begin{array}{r}2,946.0 \\
3,060.8 \\
3,060.2 \\
604.9 \\
849.3\end{array}$ \\
\hline $\begin{array}{l}3,376.5 \\
3,403.6 \\
3,410.8 \\
3,439.3 \\
3,442.9\end{array}$ & $\begin{array}{l}2 \\
1 \mathrm{~h} \\
3 \mathrm{~h} \\
1 \mathrm{~h} \\
2 \mathrm{~h}\end{array}$ & $\begin{array}{l}29,608.0 \\
29,372.3 \\
29,310.2 \\
29,067.4 \\
29,037.0\end{array}$ & $\begin{array}{l}29,917.5 \\
29,917.5 \\
31,985.0\end{array}$ & $\begin{array}{r}607.3 \\
850.1 \\
2,948.0\end{array}$ & $\begin{array}{l}4,215.94 \\
4,249.6 \\
4,284 \\
4,324 \\
4,476.7\end{array}$ & $\begin{array}{l}20 \\
6 \\
1 \mathrm{H} \\
1 \mathrm{~h} \\
4\end{array}$ & $\begin{array}{l}23,712.8 \\
23,525.0 \\
23,336 \\
23,120 \\
22,331.6\end{array}$ & $\begin{array}{l}24,705.0 \\
24,705.0 \\
24,515.5 \\
24,705.0 \\
22,937.9\end{array}$ & $\begin{array}{l}992.2 \\
1,180.0 \\
1,180 \\
1,585 \\
606.3\end{array}$ \\
\hline $\begin{array}{l}3,450.2 \\
3,454.5 \\
3,456.18 \\
3,461.9 \\
3,463.8\end{array}$ & $\begin{array}{c}2 \mathrm{~h} \\
2 \mathrm{~h} \\
15 \\
3 \mathrm{~h} \\
20 \mathrm{~h}\end{array}$ & $\begin{array}{l}28,975.6 \\
28,939.5 \\
28,925.4 \\
28,877.6 \\
28,861.8\end{array}$ & $\begin{array}{l}31,923.0 \\
31,985.0 \\
31,985.0 \\
31,923.0 \\
31,923.0\end{array}$ & $\begin{array}{l}2,947.4 \\
3,045.5 \\
3,059.6 \\
3,045.4 \\
3,061.2\end{array}$ & $\begin{array}{l}4,526.0 \\
4,534.9 \\
4,543.7 \\
4,555.44 \\
4,594.5\end{array}$ & $\begin{array}{c}2 \\
1 \\
2 \\
30 \\
6 \mathrm{~h}\end{array}$ & $\begin{array}{l}22,088.4 \\
22,045.0 \\
22,002.3 \\
21,945.6 \\
21,759.1\end{array}$ & $\begin{array}{l}22,937.9 \\
23,037.9 \\
22,994.4 \\
22,937.9 \\
22,937.9\end{array}$ & $\begin{array}{r}849.5 \\
992.9 \\
992.1 \\
992.3 \\
1,178.8\end{array}$ \\
\hline $\begin{array}{l}3,471.3 \\
3,478.6 \\
3,522.0 \\
3,527.0 \\
3,593.6\end{array}$ & $\begin{array}{l}1 \\
3 \mathrm{~h} \\
2 \\
1 \\
1\end{array}$ & $\begin{array}{l}28,799.4 \\
28,739.0 \\
28,384.9 \\
28,344.6 \\
27,819.3\end{array}$ & $\begin{array}{l}31,985.0 \\
31,923.0 \\
27,388.4 \\
27,353.7\end{array}$ & $\begin{array}{l}3,185.6 \\
3,184.0 \\
-993.5 \\
-990.9\end{array}$ & $\begin{array}{l}4,618.97 \\
4,659.2 \\
4,681.8 \\
4,686.0 \\
5,001.0\end{array}$ & $\begin{array}{l}25 \mathrm{v} \\
5 \mathrm{~h} \\
5 \mathrm{~h} \\
2 \\
1\end{array}$ & $\begin{array}{l}21,643.8 \\
21,456.9 \\
21,353.3 \\
21,334.2 \\
19,990.4\end{array}$ & $\begin{array}{l}24,705.0 \\
24,515.5 \\
22,937.9 \\
22,937.9 \\
22,937.9\end{array}$ & $\begin{array}{l}3,061.2 \\
3,058.6 \\
1,584.6 \\
1,603.7 \\
2,947.5\end{array}$ \\
\hline
\end{tabular}


TABLE 3.-Modified $\mathrm{Hg}$ lines scattered by toluene $\left(\mathrm{C}_{6} \mathrm{H}_{5} \mathrm{CH}_{3}\right)$

\begin{tabular}{|c|c|c|c|c|c|c|c|c|c|}
\hline$\lambda$ & $\begin{array}{l}\text { Inten- } \\
\text { sity }\end{array}$ & $\begin{array}{c}\nu_{\text {vac }} \\
\text { modified } \\
\text { line }\end{array}$ & $\begin{array}{c}\nu_{\nabla \mathrm{sc}} \\
\text { exciting } \\
\text { line }\end{array}$ & Shift & $\lambda$ & $\begin{array}{c}\text { Inten- } \\
\text { sity }\end{array}$ & $\begin{array}{l}\nu_{\text {Vao }} \\
\text { modified } \\
\text { line }\end{array}$ & $\begin{array}{c}\nu_{\text {V so }} \\
\text { exciting } \\
\text { line }\end{array}$ & Shift \\
\hline $\begin{array}{l}3,058.3 \\
3,104.4 \\
3,110.8 \\
3,136.1 \\
3,146.9\end{array}$ & $\begin{array}{l}1 \\
1 \\
1 \\
5 \mathrm{~h} \\
2 \mathrm{~h}\end{array}$ & $\begin{array}{l}32,688.4 \\
32,203.0 \\
32,136.8 \\
31,877.5 \\
31,768.1\end{array}$ & $\begin{array}{l}33,692.0 \\
33,085.8 \\
31,985.0\end{array}$ & $\begin{array}{r}1,003.6 \\
1,208.3 \\
216.9\end{array}$ & $\begin{array}{l}3,739.9 \\
3,758.2 \\
3,762.8 \\
3,793.9 \\
3,797.9\end{array}$ & $\begin{array}{r}1 \\
8 \\
5 \\
10 \\
1\end{array}$ & $\begin{array}{l}26,731.1 \\
26,601.0 \\
26,568.4 \\
26,350.6 \\
26,322.9\end{array}$ & $\begin{array}{l}27,353.7 \\
27,388.4 \\
27,353.7 \\
27,353.7 \\
27,353.7\end{array}$ & $\begin{array}{r}622.6 \\
787.4 \\
785.3 \\
1,003.1 \\
1,030.8\end{array}$ \\
\hline $\begin{array}{l}3,153.1 \\
3,177.2 \\
3,183.5 \\
3,187.6 \\
3,193.9\end{array}$ & $\begin{array}{l}3 \mathrm{H} \\
3 \mathrm{~h} \\
3 \mathrm{~h} \\
2 \mathrm{~h} \\
2 \mathrm{~h}\end{array}$ & $\begin{array}{l}31,705.7 \\
31,465.2 \\
31,402.9 \\
31,362.5 \\
31,300.7\end{array}$ & $\begin{array}{l}31,923.0 \\
31,985.0 \\
31,923.0 \\
31,985.0 \\
31,923.0\end{array}$ & $\begin{array}{l}217.3 \\
519.8 \\
520.1 \\
622.5 \\
622.3\end{array}$ & $\begin{array}{l}3,803.0 \\
3,823.7 \\
3,833.1 \\
3,843.5 \\
3,848.8\end{array}$ & $\begin{array}{l}6 \\
2 \mathrm{~h} \\
4 . \\
7 \mathrm{~h} \\
2\end{array}$ & $\begin{array}{l}26,287.6 \\
26,145.3 \\
26,081.2 \\
26,010.6 \\
25,974.8\end{array}$ & $\begin{array}{l}27,290.4 \\
27,353.7 \\
27,290.4 \\
27,388.4 \\
27,353.7\end{array}$ & $\begin{array}{l}1,002.8 \\
1,208.4 \\
1,209.2 \\
1,377.8 \\
1,378.9\end{array}$ \\
\hline $\begin{array}{l}3,204.3 \\
3,210.6 \\
3,226.8 \\
3,229.7 \\
3,233.2\end{array}$ & $\begin{array}{c}6 \mathrm{~h} \\
6 \mathrm{~h} \\
10 \\
3 \\
12\end{array}$ & $\begin{array}{l}31,199.1 \\
31,137.9 \\
30,981.5 \\
30,953.7 \\
30,920.2\end{array}$ & $\begin{array}{l}31,985.0 \\
31,923.0 \\
31,985.0 \\
31,985.0 \\
31,923.0\end{array}$ & $\begin{array}{r}785.9 \\
785.1 \\
1,003.5 \\
1,031.3 \\
1,002.8\end{array}$ & $\begin{array}{l}3,877.0 \\
3,882.6 \\
4,011.6 \\
4,085.8 \\
4,091.6\end{array}$ & $\begin{array}{c}15 \mathrm{~h} \\
3 \\
1 \mathrm{~h} \\
5 \mathrm{~h} \\
3 \mathrm{~h}\end{array}$ & $\begin{array}{l}25,785.8 \\
25,748.7 \\
24,920.7 \\
24,468.1 \\
24,433.4\end{array}$ & $\begin{array}{l}27,388.4 \\
27,353.7 \\
24,705.0 \\
27,388.4 \\
27,353.7\end{array}$ & $\begin{array}{l}1,602.6 \\
1,605.0 \\
-215.7(?) \\
2,920.3 \\
2,920.3\end{array}$ \\
\hline $\begin{array}{l}3,236.0 \\
3,248.3 \\
3,254.8 \\
3,266.5 \\
3,273.0\end{array}$ & $\begin{array}{l}3 \\
7 \\
7 \\
2 \\
2\end{array}$ & $\begin{array}{l}30,893.5 \\
30,776.5 \\
30,715.0 \\
30,605.0 \\
30,544.2\end{array}$ & $\begin{array}{l}31,923.0 \\
31,985.0 \\
31,923.0 \\
31,985.0 \\
31,923.0\end{array}$ & $\begin{array}{l}1,029.5 \\
1,208.5 \\
1,208.0 \\
1,380.0 \\
1,378.8\end{array}$ & $\begin{array}{l}4,114.6 \\
4,124.9 \\
4,133.9 \\
4,151.2 \\
4,166.3\end{array}$ & $\begin{array}{c}1 \mathrm{~h} \\
10 \mathrm{~h} \\
5 \\
4 \mathrm{~h} \\
1 \mathrm{~h}\end{array}$ & $\begin{array}{l}24,296.9 \\
24,236.2 \\
24,183.4 \\
24,082.6 \\
23,995.4\end{array}$ & $\begin{array}{l}24,515.5 \\
27,290.4 \\
24,705.0 \\
24,705.0 \\
24,515.5\end{array}$ & $\begin{array}{r}218.6 \\
3,054.2 \\
521.6 \\
622.4 \\
520.1\end{array}$ \\
\hline $\begin{array}{l}3,278.7 \\
3,290.8 \\
3,297.4 \\
3,313.9 \\
3,400.8\end{array}$ & $\begin{array}{l}1 \mathrm{~h} \\
4 \mathrm{~h} \\
4 \mathrm{~h} \\
1 \text { (?) } \\
1\end{array}$ & $\begin{array}{l}30,491.1 \\
30,379.0 \\
30,318.2 \\
30,167.3 \\
29,396.4\end{array}$ & $\begin{array}{l}31,985.0 \\
31,923.0 \\
33,085.8 \\
29,917.5\end{array}$ & $\begin{array}{l}1,606.0 \\
1,604.8 \\
2,918.5(?) \\
521.1\end{array}$ & $\begin{array}{l}4,179.6 \\
4,217.92 \\
4,223.1 \\
4,252.2 \\
4,255.3\end{array}$ & $\begin{array}{l}10 \\
20 \\
4 \\
1 \\
5\end{array}(?)$ & $\begin{array}{l}23,919.0 \\
23,701.7 \\
23,672.6 \\
23,510.6 \\
23,493.5\end{array}$ & $\begin{array}{l}24,705.0 \\
24,705.0 \\
24,705.0 \\
24,515.5 \\
24,705.0\end{array}$ & $\begin{array}{l}786.0 \\
1,003.3 \\
1,032.4 \\
1,004.9(?) \\
1,211.5\end{array}$ \\
\hline $\begin{array}{l}3,406.3 \\
3,412.6 \\
3,439.6 \\
3,447.0 \\
3,455.4\end{array}$ & $\begin{array}{l}1 \\
1 \\
5 \mathrm{~h} \\
5 \mathrm{~h} \\
3 \mathrm{~h}\end{array}$ & $\begin{array}{l}29,349.0 \\
29,294.8 \\
29,064.8 \\
29,002.5 \\
28,932.0\end{array}$ & $\begin{array}{l}29,917.5 \\
31,985.0 \\
31,923.0 \\
31,985.0\end{array}$ & $\begin{array}{r}622.7 \\
2,920.2 \\
2,920.5 \\
3,053.0\end{array}$ & $\begin{array}{l}4,286.0 \\
4,389.0 \\
4,400.3 \\
4,460.0 \\
4,480.1\end{array}$ & $\begin{array}{l}2 \mathrm{~h} \\
2 \mathrm{~h} \\
5 \mathrm{~h} \\
4 \\
3\end{array}$ & $\begin{array}{l}23,325.2 \\
22,777.9 \\
22,719.4 \\
22,415.3 \\
22,314.7\end{array}$ & $\begin{array}{l}24,705.0 \\
22,994.4 \\
22,937.9 \\
22,937.9 \\
22,937.9\end{array}$ & $\begin{array}{r}1,379.8 \\
216.5 \\
218.5 \\
522.6 \\
623.2\end{array}$ \\
\hline $\begin{array}{l}3,457.5 \\
3,460.9 \\
3,463.0 \\
3,482.4\end{array}$ & $\begin{array}{l}5 \\
4 \mathrm{~h} \\
6 \mathrm{~h} \\
4\end{array}$ & $\begin{array}{l}28,914.4 \\
28,886.0 \\
28,868.5 \\
28,707.6\end{array}$ & $\begin{array}{l}29,917.5 \\
29,917.5 \\
31,923.0 \\
29,917.5\end{array}$ & $\begin{array}{l}1,003.1 \\
1,031.5 \\
3,054.5 \\
1,209.9\end{array}$ & $\begin{array}{l}4,501.3 \\
4,513.01 \\
4,557.70 \\
4,563.8\end{array}$ & $\begin{array}{l}1(?) \\
10 \\
20 \\
5\end{array}$ & $\begin{array}{l}22,209.6 \\
22,152.0 \\
21,934.8 \\
21,905.4\end{array}$ & $\begin{array}{l}22,994.4 \\
22,937.9 \\
22,937.9 \\
22,937.9\end{array}$ & $\begin{array}{r}784.8(?) \\
785.9 \\
1,003.1 \\
1,032.5\end{array}$ \\
\hline $\begin{array}{l}3,503.3 \\
3,521.1 \\
3,531.0 \\
3,593.7\end{array}$ & $\begin{array}{l}1 \\
1 \\
1 \\
1\end{array}$ & $\begin{array}{l}28,536.4 \\
28,392.1 \\
28,312.5 \\
27,818.6\end{array}$ & $\begin{array}{l}29,917.5 \\
27,388.4 \\
29,917.5\end{array}$ & $\begin{array}{r}1,381.1 \\
-1,003.7 \\
1,605.0\end{array}$ & $\begin{array}{l}4,589.6 \\
4,601.4 \\
4,617.0\end{array}$ & $\begin{array}{c}10 \mathrm{~h} \\
5 \\
20 \mathrm{hd}\end{array}$ & $\begin{array}{l}21,782.3 \\
21,726.4 \\
21,653.0\end{array}$ & $\begin{array}{r}\left\{\begin{array}{l}22,994.4 \\
24.705 .0\end{array}\right. \\
22,937.9 \\
24,705.0\end{array}$ & $\begin{array}{l}1,212.1(?) \\
2,922.7 \\
1,211.5(?) \\
3,052.0\end{array}$ \\
\hline $\begin{array}{l}3,621.4 \\
3,721.0 \\
3,725.9 \\
3,734.6\end{array}$ & $\begin{array}{r}2 \mathrm{~h} \\
10 \mathrm{~h} \\
2 \mathrm{~h} \\
8 \mathrm{~h}\end{array}$ & $\begin{array}{l}27,605.8 \\
26,866.9 \\
26,831.6 \\
26,769.0\end{array}$ & $\begin{array}{r}27,388.4 \\
27,353.7 \\
27,388.4\end{array}$ & $\begin{array}{l}521.5 \\
522.1 \\
619.4 \\
521.4\end{array}$ & $\begin{array}{l}4,637.1 \\
4,658.6 \\
4,686 \\
4,994.1\end{array}$ & $\begin{array}{l}1 \mathrm{~h} \\
2 \mathrm{~h} \\
6 \mathrm{hd} \\
3\end{array}$ & $\begin{array}{l}21,559.2 \\
21,459.7 \\
21,334 \\
20,018.1\end{array}$ & $\begin{array}{l}22,937.9 \\
24,515.5 \\
22,937.9 \\
22,937.9\end{array}$ & $\begin{array}{l}1,378.7 \\
3,055.8 \\
1,604 \\
2,919.8\end{array}$ \\
\hline
\end{tabular}


TABLE 4.-Modified $\mathrm{Hg}$ lines scattered by chloroform $\left(\mathrm{CHCl}_{3}\right)$

\begin{tabular}{|c|c|c|c|c|c|c|c|c|c|}
\hline$\lambda$ & $\begin{array}{l}\text { Inten- } \\
\text { sity }\end{array}$ & $\begin{array}{l}\nu_{\mathrm{V} a c} \text { modi- } \\
\text { fied line }\end{array}$ & $\begin{array}{c}\nu_{\nabla \text { so }} \text { excit- } \\
\text { ing line }\end{array}$ & Shift & $\lambda$ & $\begin{array}{l}\text { Inten- } \\
\text { sity }\end{array}$ & $\begin{array}{l}\nu_{\nabla \text { ac }} \text { modi } \\
\text { fied line }\end{array}$ & $\begin{array}{c}\nu_{\text {Yac excit- }} \\
\text { ing line }\end{array}$ & Shift \\
\hline $\begin{array}{l}3,038.5 \\
3,055.1 \\
3,061.5 \\
3,067.3 \\
3,083.8\end{array}$ & $\begin{array}{l}2 \\
1 \\
1 \\
1 \\
3\end{array}$ & $\begin{array}{l}32,901.4 \\
32,722.7 \\
32,654.3 \\
32,592.5 \\
32,418.1\end{array}$ & $\begin{array}{l}33,085.8 \\
31,985.0 \\
31,923.0 \\
33,085.8\end{array}$ & $\begin{aligned} & 363.1(?) \\
- & 669.3 \\
- & 669.5 \\
& 667.7\end{aligned}$ & $\begin{array}{l}3,690.1 \\
3,699.2 \\
3,704.1 \\
3,712.8 \\
3,716.7\end{array}$ & $\begin{array}{r}5 \\
20 \\
6 \\
8 \\
2\end{array}$ & $\begin{array}{l}27,091.9 \\
27,025.2 \\
26,989.5 \\
26,926.2 \\
26,898.0\end{array}$ & $\begin{array}{l}27,353.7 \\
27,388.4 \\
27,353.7 \\
27,290.4 \\
29,917.5\end{array}$ & $\begin{array}{r}261.8 \\
363.2 \\
364.2 \\
364.2 \\
3,019.5\end{array}$ \\
\hline $\begin{array}{l}3,085.8 \\
3,090.1 \\
3,096.0 \\
3,100.2 \\
3,106.2\end{array}$ & $\begin{array}{l}1 \\
2 \\
3 \\
4 \\
5\end{array}$ & $\begin{array}{l}32,397.1 \\
32,352.0 \\
32,290.4 \\
32,246.7 \\
32,184.4\end{array}$ & $\begin{array}{l}31,985.0 \\
31,923.0 \\
31,985.0 \\
31,923.0\end{array}$ & $\begin{array}{l}-367.0 \\
-367.4 \\
-261.7 \\
-261.4\end{array}$ & $\begin{array}{l}3,741.2 \\
3,746.1 \\
3,833.9 \\
3,939.7 \\
3,987.7\end{array}$ & $\begin{array}{l}25 \\
7 \\
2 \mathrm{~h} \\
1 \\
1\end{array}$ & $\begin{array}{l}26,721.8 \\
26,686.9 \\
26,075.7 \\
25,375.5 \\
25,070.0\end{array}$ & $\begin{array}{l}27,388.4 \\
27,353.7 \\
27,290.4 \\
24,705.0 \\
24,705.0\end{array}$ & $\begin{array}{r}666.6 \\
666.8 \\
1,214.7 \\
-669.5 \\
-365.0\end{array}$ \\
\hline $\begin{array}{l}3,151.3 \\
3,157.4 \\
3,161.7 \\
3,167.9 \\
3,192.2\end{array}$ & $\begin{array}{r}7 \\
10 \\
8 \\
10 \\
10\end{array}$ & $\begin{array}{l}31,723.8 \\
31,662.5 \\
31,619.4 \\
31,557.5 \\
31,317.3\end{array}$ & $\begin{array}{l}31,985.0 \\
31,923.0 \\
31,985.0 \\
31,923.0 \\
31,985.0\end{array}$ & $\begin{array}{l}261.2 \\
260.5 \\
365.6 \\
365.5 \\
667.7\end{array}$ & $\begin{array}{l}4,004.5 \\
4,017.8 \\
4,090.0 \\
4,102.1 \\
4,118.6\end{array}$ & $\begin{array}{r}8 \\
1 \\
20 \\
25 \\
6\end{array}$ & $\begin{array}{l}24,964.9 \\
24,882.2 \\
24,443.3 \\
24,370.9 \\
24,273.2\end{array}$ & $\begin{array}{l}24,705.0 \\
24,515.5 \\
24,705.0 \\
27,388.4 \\
27,290.4\end{array}$ & $\begin{array}{r}-259.9 \\
-366.7 \\
261.7 \\
3,017.5 \\
3,017.2\end{array}$ \\
\hline $\begin{array}{l}3,198.5 \\
3,201.7 \\
3,208.0 \\
3,248.9 \\
3,255.5\end{array}$ & $\begin{array}{l}12 \\
3 \mathrm{~h} \\
5 \mathrm{hd}(?) \\
2 \mathrm{~h} \\
3 \mathrm{~h}\end{array}$ & $\begin{array}{l}31,255.7 \\
31,224.4 \\
31,163.1 \\
30,770.8 \\
30,708.4\end{array}$ & $\begin{array}{l}31,923.0 \\
31,985.0 \\
31,923.0 \\
31,985.0 \\
31,923.0\end{array}$ & $\begin{array}{r}667.3 \\
760.6 \\
759.9 \\
1,214.2 \\
1,214.6\end{array}$ & $\begin{array}{l}4,121.5 \\
4,139.5 \\
4,159.3 \\
4,175.0 \\
4,192.1\end{array}$ & $\begin{array}{l}4 \\
5 \\
20 \\
15 \mathrm{~h} \\
4\end{array}$ & $\begin{array}{l}24,256.2 \\
24,148.4 \\
24,035.8 \\
23,945.0 \\
23,848.0\end{array}$ & $\begin{array}{l}24,515.5 \\
24,515.5 \\
24,705.0 \\
24,705.0 \\
24,515.5\end{array}$ & $\begin{array}{l}259.3 \\
367.1 \\
669.2 \\
760.0 \\
667.5\end{array}$ \\
\hline $\begin{array}{l}3,259.3 \\
3,268.3 \\
3,278.4 \\
3,301.2 \\
3,312.7\end{array}$ & $\begin{array}{l}1 \\
1 \\
1 \\
3 \\
4\end{array}$ & $\begin{array}{l}30,672.6 \\
30,588.2 \\
30,493.9 \\
30,283.3 \\
30,178.2\end{array}$ & $\begin{array}{l}33,692.0 \\
29,917.5 \\
29,917.5 \\
29,917.5\end{array}$ & $\begin{array}{l}3,019.4 \\
-670.7 \\
-365.8 \\
-260.7\end{array}$ & $\begin{array}{l}4,208.1 \\
4,235.2 \\
4,256.1 \\
4,290.2 \\
4,299.1\end{array}$ & $\begin{array}{l}1 \mathrm{~h} \\
3 \\
4 \mathrm{~h} \\
5 \\
1\end{array}$ & $\begin{array}{l}23,757.0 \\
23,605.0 \\
23,489.1 \\
23,302.4 \\
23,254.2\end{array}$ & $\begin{array}{l}24,515.5 \\
22,937.9 \\
24,705.0 \\
22,937.9\end{array}$ & $\begin{array}{r}758.5 \\
-667.1 \\
1,215.9 \\
-364.5\end{array}$ \\
\hline $\begin{array}{l}3,325.1 \\
3,371.0 \\
3,376.2 \\
3,383.0 \\
3,417.9\end{array}$ & $\begin{array}{c}2 \mathrm{~h} \\
10 \\
1 \\
10 \\
10\end{array}$ & $\begin{array}{l}30,065.7 \\
29,656.3 \\
29,610.6 \\
29,551.1 \\
29,249.4\end{array}$ & $\begin{array}{r}33,085.8 \\
29,917.5 \\
29,917.5 \\
29,917.5\end{array}$ & $\begin{array}{r}3,020.1 \\
261.2 \\
\\
366.4 \\
668.1\end{array}$ & $\begin{array}{l}4,309.6 \\
4,389.0 \\
4,397.8 \\
4,408.8 \\
4,418.0\end{array}$ & $\begin{array}{l}8 \\
3 \mathrm{~h} \\
1 \mathrm{~h} \\
20 \\
1\end{array}$ & $\begin{array}{l}23,197.5 \\
22,778.1 \\
22,732.2 \\
22,675.6 \\
22,628.3\end{array}$ & $\begin{array}{l}22,937.9 \\
23,037.9 \\
22,994.4 \\
22,937.9 \\
22,994.4\end{array}$ & $\begin{array}{r}-259.6 \\
259.8 \\
262.2 \\
262.3 \\
366.1\end{array}$ \\
\hline $\begin{array}{l}3,451.3 \\
3,458.8 \\
3,483.0 \\
3,496.6 \\
3,567.4\end{array}$ & $\begin{array}{c}15 \mathrm{~h} \\
20 \mathrm{~h} \\
2 \mathrm{~h} \\
1 \mathrm{H} \\
1\end{array}$ & $\begin{array}{l}28,965.9 \\
28,903.5 \\
28,702.7 \\
28,591.1 \\
28,023.6\end{array}$ & $\begin{array}{l}31,985.0 \\
31,923.0 \\
29,917.5 \\
27,353.7\end{array}$ & $\begin{array}{c}3,019.1 \\
3,019.5 \\
1,214.8 \\
-669.9\end{array}$ & $\begin{array}{l}4,429.2 \\
4,468.9 \\
4,478.3 \\
4,489.4 \\
4,508.1\end{array}$ & $\begin{array}{l}25 \\
1(?) \\
2 \\
30 \\
20 \mathrm{~h}\end{array}$ & $\begin{array}{l}22,571.1 \\
22,370.6 \\
22,323.6 \\
22,268.5 \\
22,176.1\end{array}$ & $\begin{array}{l}22,937.9 \\
23,037.9 \\
22,994.4 \\
22,937.9 \\
22,937.9\end{array}$ & $\begin{array}{l}366.8 \\
667.3(?) \\
670.8 \\
669.4 \\
761.8\end{array}$ \\
\hline $\begin{array}{l}3,575.5 \\
3,601.8 \\
3,606.6 \\
3,620.1 \\
3,628.5 \\
3,685.2\end{array}$ & $\begin{array}{l}2 \\
5 \\
2 \\
2 \\
2(?) \\
10\end{array}$ & $\begin{array}{l}27,960.2 \\
27,756.0 \\
27,719.1 \\
27,615.7 \\
27,551.8 \\
27,127.9\end{array}$ & $\begin{array}{l}27,290.4 \\
27,388.4 \\
27,353.7 \\
27,353.7 \\
27,290.4 \\
27,388.4\end{array}$ & $\begin{array}{r}-669.8 \\
-367.6 \\
-365.4 \\
-262.0 \\
-261.4 \\
260.5\end{array}$ & $\begin{array}{l}4,602.4 \\
4,610.0 \\
4,650.3 \\
5,006.1 \\
5,019.1\end{array}$ & $\begin{array}{r}3 \\
15 \\
2 \\
1 \\
7\end{array}$ & $\begin{array}{l}21,721.7 \\
21,685.9 \\
21,498.0 \\
19,970.0 \\
19,918.4\end{array}$ & $\begin{array}{l}22,937.9 \\
24,705.0 \\
24,515.5 \\
20,334.5 \\
22,937.9\end{array}$ & $\begin{array}{l}1,216.2 \\
3,019.1 \\
3,017.5 \\
664.5(?) \\
3,019.5\end{array}$ \\
\hline
\end{tabular}




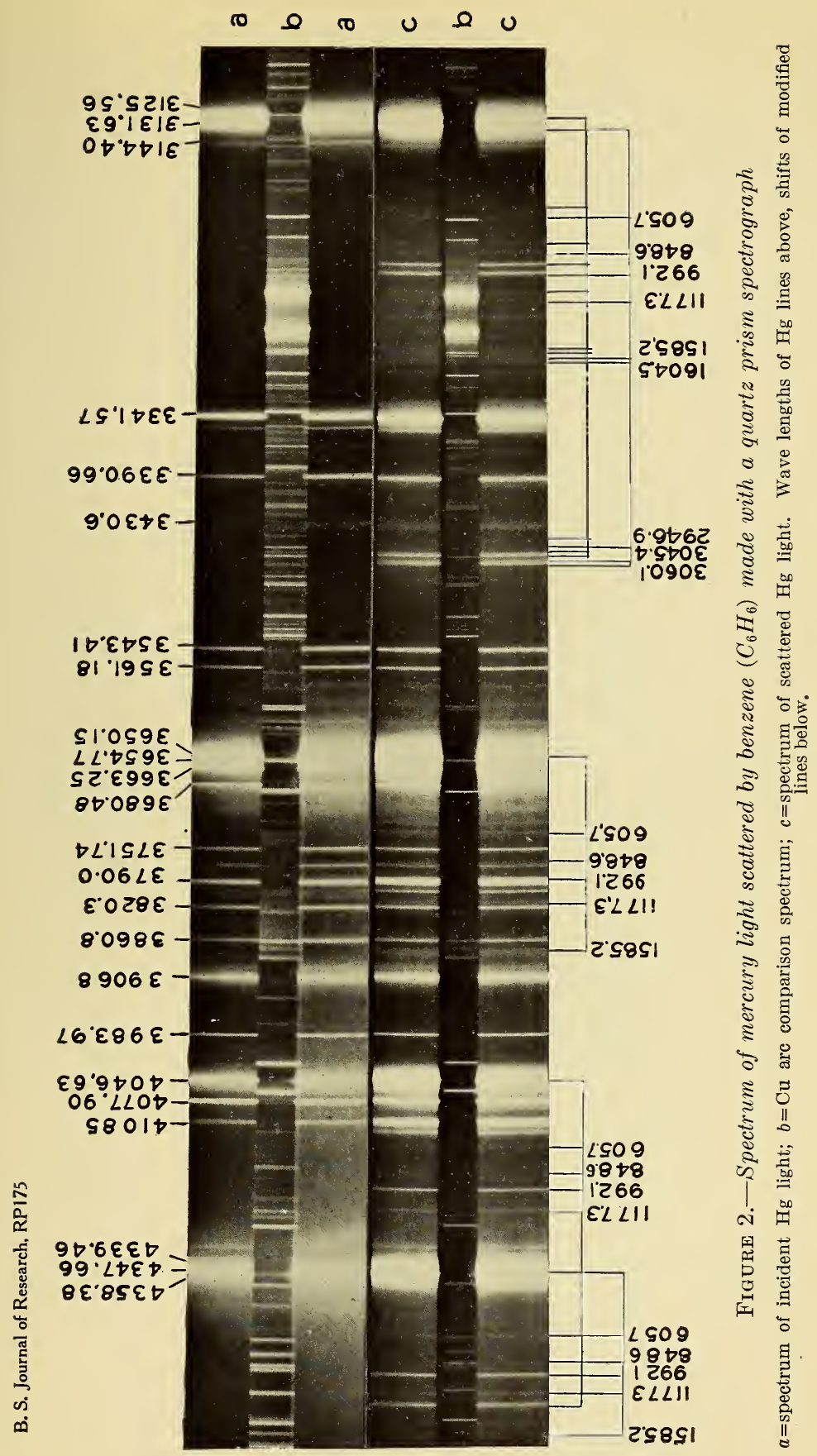




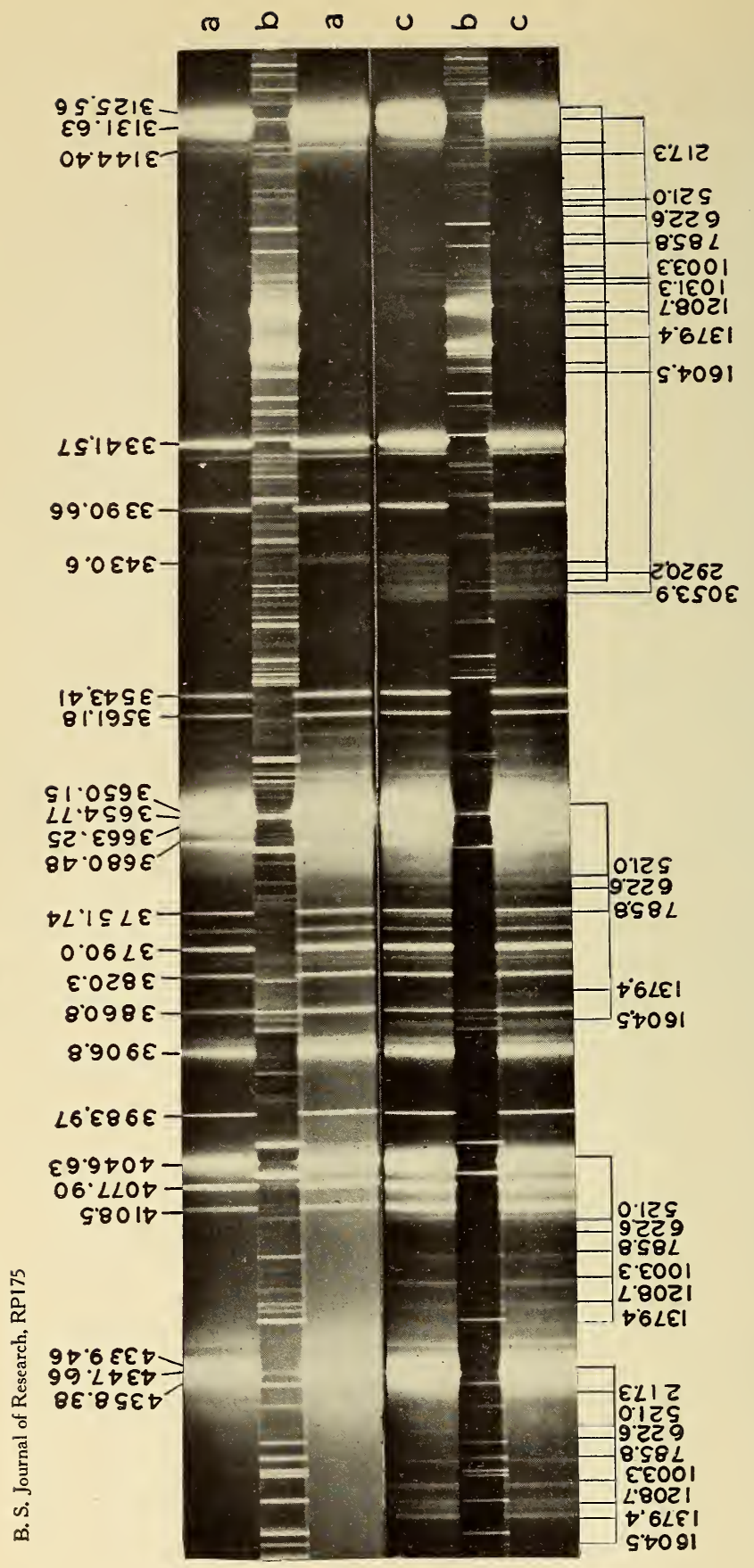

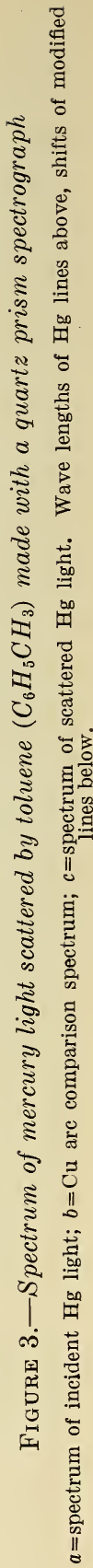




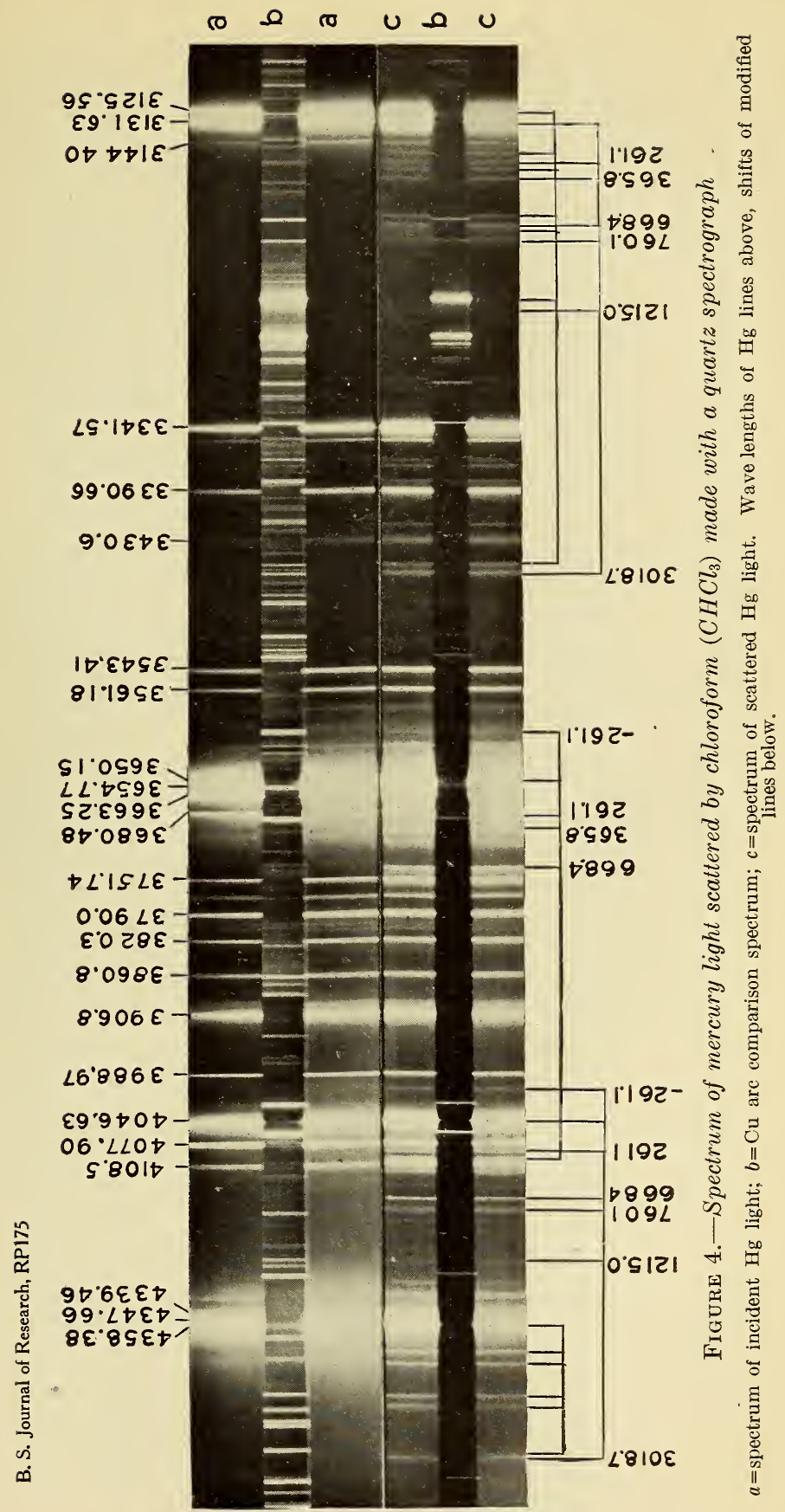




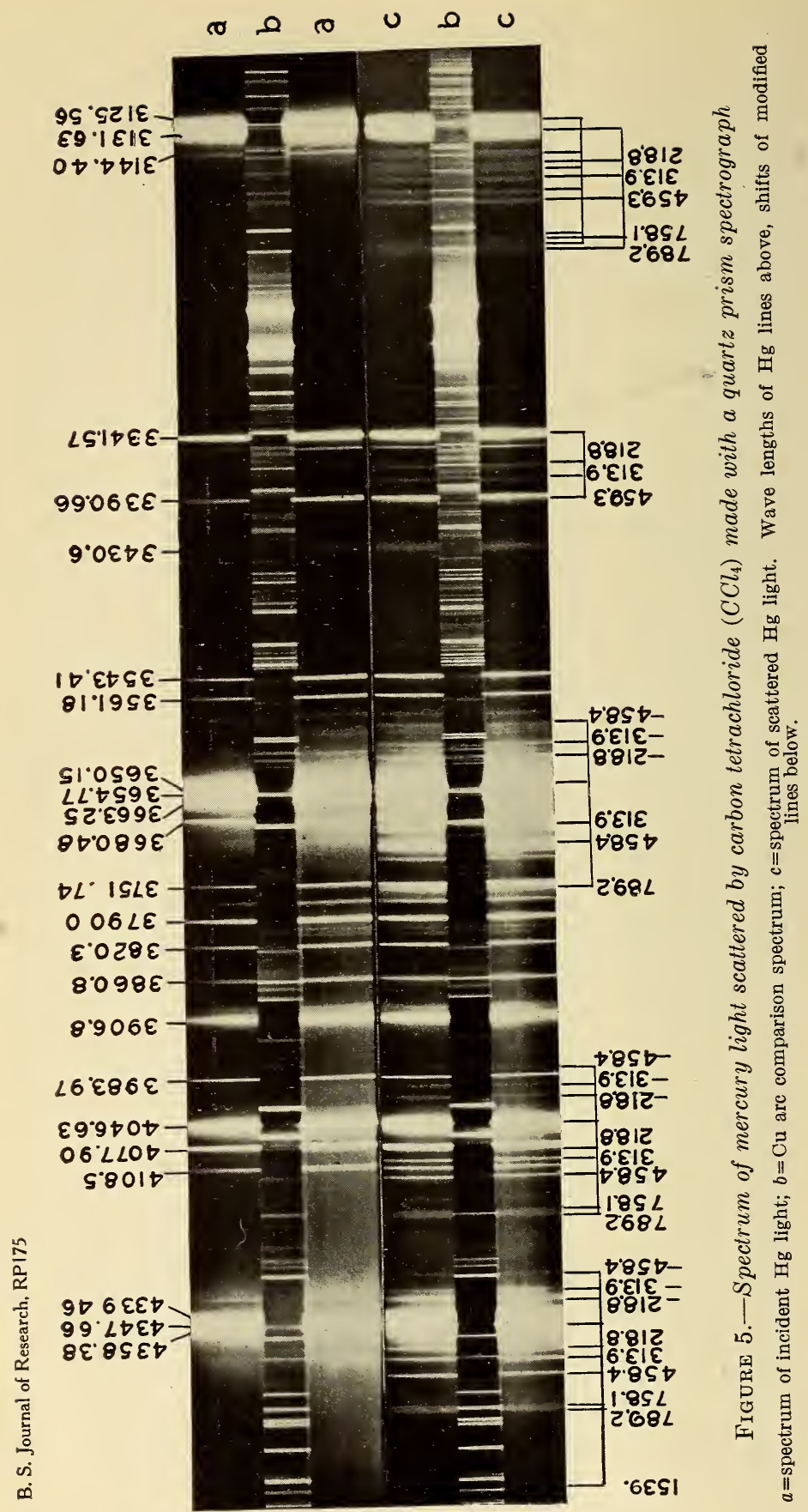




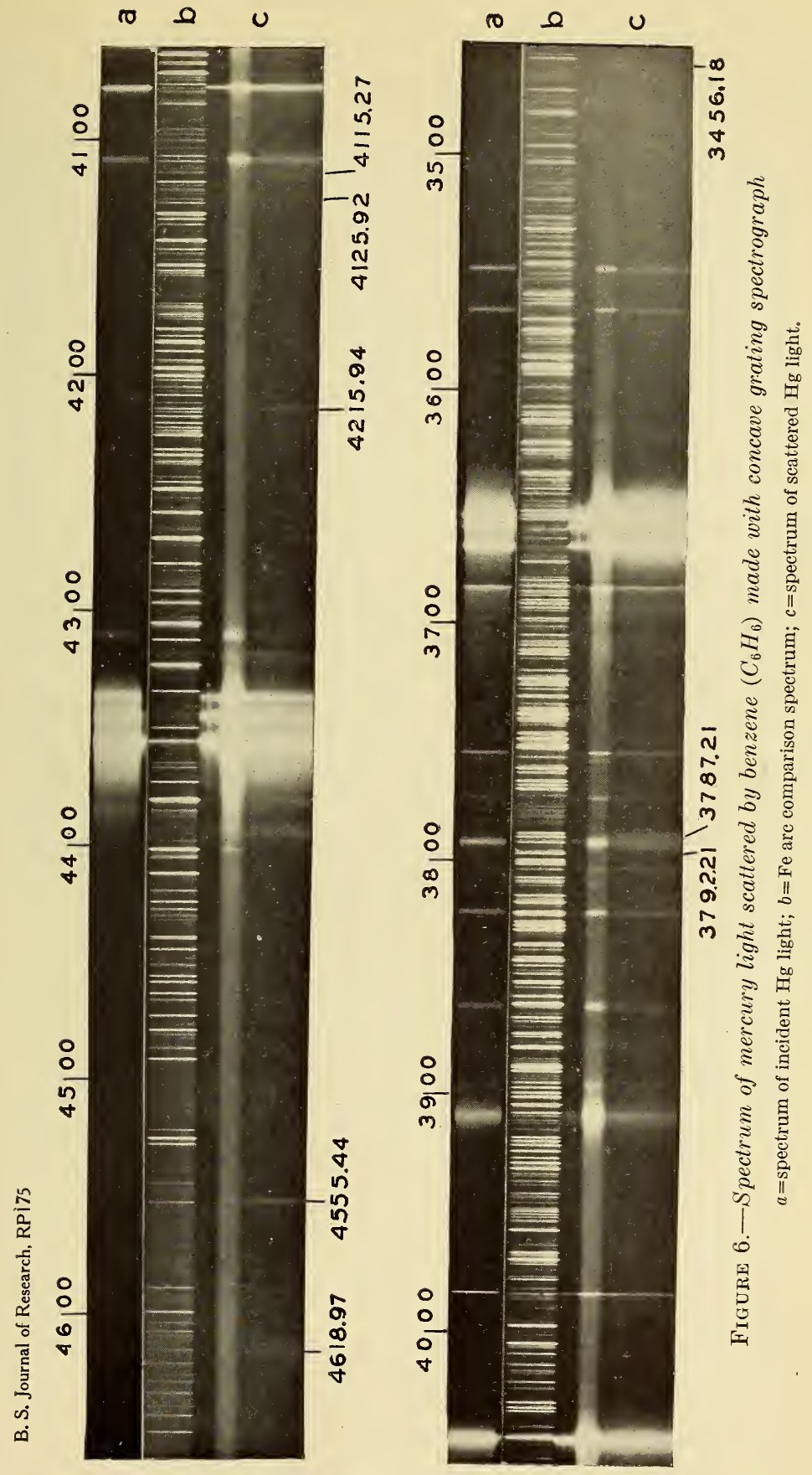


TABLE 5.-Modified $\mathrm{Hg}$ lines scattered by carbon tetrachloride $\left(\mathrm{CCl}_{4}\right)$

\begin{tabular}{|c|c|c|c|c|c|c|c|c|c|}
\hline$\lambda$ & $\begin{array}{l}\text { Inten- } \\
\text { sity }\end{array}$ & $\begin{array}{l}\nu_{\mathrm{rac}} \text { modi- } \\
\text { fied line }\end{array}$ & $\begin{array}{l}\nu_{\text {vac excit- }} \\
\text { ing line }\end{array}$ & Shift & $\lambda$ & $\begin{array}{l}\text { Inten- } \\
\text { sity }\end{array}$ & $\begin{array}{l}\nu_{\text {Vac }} \text { modi- } \\
\text { fied line }\end{array}$ & $\begin{array}{l}D_{\text {rac excit- }} \text { ing line }\end{array}$ & Shift \\
\hline $\begin{array}{l}\text { 3, 061. } 2 \\
3,081.3 \\
3,087.1 \\
3,095.0 \\
3,101.0 \\
3,104.3\end{array}$ & $\begin{array}{l}1 \mathrm{~h} \\
1 \mathrm{~h} \\
1 \mathrm{~h} \\
2 \mathrm{~h} \\
2 \mathrm{~h} \\
2 \mathrm{~h}\end{array}$ & $\begin{array}{l}32,625.5 \\
32,44.4 \\
32,383.5 \\
32,300.8 \\
32,238.3 \\
32,204.1\end{array}$ & $\begin{array}{l}33,085.8 \\
31,95.0 \\
31,923.0 \\
31,985.0 \\
31,923.0 \\
31,985.0\end{array}$ & $\begin{array}{r}459.7 \\
-459.4 \\
-460.5 \\
-315.8 \\
-315.3 \\
-219.1\end{array}$ & $\begin{array}{l}3,684.2 \\
3,692.36 \\
3,697.20 \\
3,705.84 \\
3,712.28\end{array}$ & $\begin{array}{r}5 \mathrm{~h} \\
30 \mathrm{~h} \\
10 \mathrm{~h} \\
8 \mathrm{~h} \\
40 \mathrm{~h}\end{array}$ & $\begin{array}{l}27,135.2 \\
27,075.3 \\
27,039.8 \\
26,976.8 \\
26,930.0\end{array}$ & $\begin{array}{l}27,353.7 \\
27,388.4 \\
27,353.7 \\
27,290.4 \\
27,388.4\end{array}$ & $\begin{array}{l}218.5 \\
313.1 \\
313.9 \\
313.6 \\
458.4\end{array}$ \\
\hline $\begin{array}{l}3,110.2 \\
3,136.0 \\
3,147.1 \\
3,153.2 \\
3,156.6\end{array}$ & $\begin{array}{l}2 \mathrm{~h} \\
5 \\
5 \mathrm{~h} \\
6 \mathrm{~h} \\
6 \mathrm{~h}\end{array}$ & $\begin{array}{l}32,143.0 \\
31,878.5 \\
31,766.1 \\
31,704.7 \\
31,670.5\end{array}$ & $\begin{array}{l}31,985.0 \\
31,923.0 \\
31,985.0\end{array}$ & $\begin{array}{r}-220.0 \\
218.9 \\
218.3 \\
314.5\end{array}$ & $\begin{array}{l}3,717.28 \\
3,725.94 \\
3,758.6 \\
3,972.7 \\
3,995.8\end{array}$ & $\begin{array}{r}15 \mathrm{~h} \\
15 \mathrm{~h} \\
6 \mathrm{~h} \\
4 \mathrm{~h} \\
5 \mathrm{~h}\end{array}$ & $\begin{array}{l}26,894.3 \\
26,831.3 \\
26,598.1 \\
25,164.7 \\
25,019.2\end{array}$ & $\begin{array}{l}27,353.7 \\
27,290.4 \\
27,388.4 \\
24,705.0 \\
24,705.0\end{array}$ & $\begin{array}{r}459.4 \\
459.1 \\
790.3 \\
-459.7 \\
-314.2\end{array}$ \\
\hline & $\begin{array}{r}7 \mathrm{~h} \\
8 \mathrm{~h} \\
10 \mathrm{~h} \\
3 \mathrm{~h} \\
3 \mathrm{~h}\end{array}$ & $\begin{array}{l}31,609.4 \\
31,526.7 \\
31,465.2 \\
31,227.3 \\
31,196.2\end{array}$ & $\begin{array}{l}31,923.0 \\
31,985.0 \\
31,923.0 \\
31,985.0 \\
31,985.0\end{array}$ & $\begin{array}{l}313.6 \\
458.3 \\
457.8 \\
757.7 \\
788.8\end{array}$ & $\begin{array}{l}4,011.0 \\
4,082.7 \\
4,098.79 \\
4,114.3 \\
4,123.04\end{array}$ & $\begin{array}{r}7 \mathrm{~h} \\
10 \mathrm{~h} \\
15 \mathrm{~h} \\
2 \\
25 \mathrm{~h}\end{array}$ & $\begin{array}{l}24,924.4 \\
24,486.7 \\
24,390.6 \\
24,299.2 \\
24,247.1\end{array}$ & $\begin{array}{l}24,705.0 \\
24,705.0 \\
24,705.0 \\
24,515.5 \\
24,705.0\end{array}$ & $\begin{array}{r}-219.4 \\
218.3 \\
314.4 \\
216.3 \\
457.9\end{array}$ \\
\hline & $\begin{array}{l}4 \mathrm{~h} \\
4 \mathrm{~h} \\
2 \\
2 \\
3\end{array}$ & & $\begin{array}{l}31,923.0 \\
31,923.0 \\
29,917.5 \\
29,917.5 \\
29,917.5\end{array}$ & $\begin{array}{r}757.0 \\
789.0 \\
-458.8 \\
-314.5 \\
-218.9\end{array}$ & $\begin{array}{l}4,130.7 \\
4,155.5 \\
4,174.8 \\
4,180.4 \\
4,273.1\end{array}$ & $\begin{array}{l}3 \\
5 \mathrm{~h} \\
6 \mathrm{~h} \\
8 \mathrm{~h} \\
5 \mathrm{~h}\end{array}$ & & $\begin{array}{l}24,515.5 \\
24,515.5 \\
24,705.0 \\
24,705.0 \\
22,937.9\end{array}$ & $\begin{array}{r}313.3 \\
457.8 \\
758.5 \\
790.6 \\
-457.8\end{array}$ \\
\hline $\begin{array}{l}3,366.3 \\
3,377.0 \\
3,393.6 \\
3,589.7 \\
3,594.1\end{array}$ & $\begin{array}{c}10 \mathrm{~h} \\
10 \mathrm{~h} \\
15 \\
7 \mathrm{~h} \\
2\end{array}$ & $\begin{array}{l}29,697.7 \\
29,603.6 \\
29,458.8 \\
27,849.6 \\
27,815.5\end{array}$ & $\begin{array}{l}29,917.5 \\
29,917.5 \\
29,917.5 \\
27,388.4 \\
27,353.7\end{array}$ & $\begin{array}{r}219.8 \\
313.9 \\
458.7 \\
-461.2 \\
-461.8\end{array}$ & & $\begin{array}{r}5 \mathrm{~h} \\
4 \mathrm{~h} \\
3 \mathrm{H} \\
10 \mathrm{~h} \\
20 \mathrm{~h}\end{array}$ & $\begin{array}{l}23,251.5 \\
23,156.1 \\
22,777.8 \\
22,719.9 \\
22,623.7\end{array}$ & $\begin{array}{l}22,937.9 \\
22,937.9 \\
22,994.4 \\
22,937.9 \\
22,937.9\end{array}$ & $\begin{array}{c}-313.8 \\
-218.2 \\
216.6(? \\
218.0 \\
314.2\end{array}$ \\
\hline $\begin{array}{l}3,602.3 \\
3,609.0 \\
3,613.5 \\
3,621.1 \\
3,625.7\end{array}$ & $\begin{array}{c}2 \\
10 \mathrm{~h} \\
2 \mathrm{~h} \\
15 \mathrm{~h} \\
2\end{array}$ & $\begin{array}{l}27,752.2 \\
27,700.6 \\
27,666.1 \\
27,608.1 \\
27,573.0\end{array}$ & $\begin{array}{l}27,290.4 \\
27,388.4 \\
27,353.7 \\
27,388.4 \\
27,353.7\end{array}$ & $\begin{array}{l}-461.8 \\
-312.2 \\
-312.4 \\
-219.7 \\
-219.3\end{array}$ & $\begin{array}{l}4,436.0 \\
4,447.3 \\
4,507.6 \\
4,513.8 \\
4,671.8\end{array}$ & $\begin{array}{r}1 \mathrm{~h} \\
40 \mathrm{~h} \\
5 \mathrm{~h} \\
6 \mathrm{~h} \\
1 \mathrm{~h}\end{array}$ & $\begin{array}{l}22,536.5 \\
22,479.3 \\
22,178.6 \\
22,148.1 \\
21,399.1\end{array}$ & $\begin{array}{l}22,994.4 \\
22,937.9 \\
22,937.9 \\
22,937.9 \\
22,937.9\end{array}$ & $\begin{array}{r}457.9 \\
458.6 \\
759.3 \\
789.8 \\
1,538.8\end{array}$ \\
\hline
\end{tabular}

Wave number and intensity data for modified lines of the four liquids are rearranged in Tables $6,7,8$, and 9 where the lines are classified in columns headed by the shift numbers so that connections with the exciting lines and certain relations between intensities become more obvious. It is seen that intensities of modified lines are roughly parallel with those of the exciting lines and the opposing tendency of "Stokes" and "anti-Stokes" lines is clearly brought out. Gaps in these tables are accounted for either by the masking action of other mercury lines, or by expected low intensity of the modified lines, or because the missing lines fall outside the range of observations. Portions of the spectrograms of mercury light scattered by the liquids dealt with in this paper are reproduced in Figures 2, 3, 4, 5, and 6. $101062^{\circ}-30-9$ 


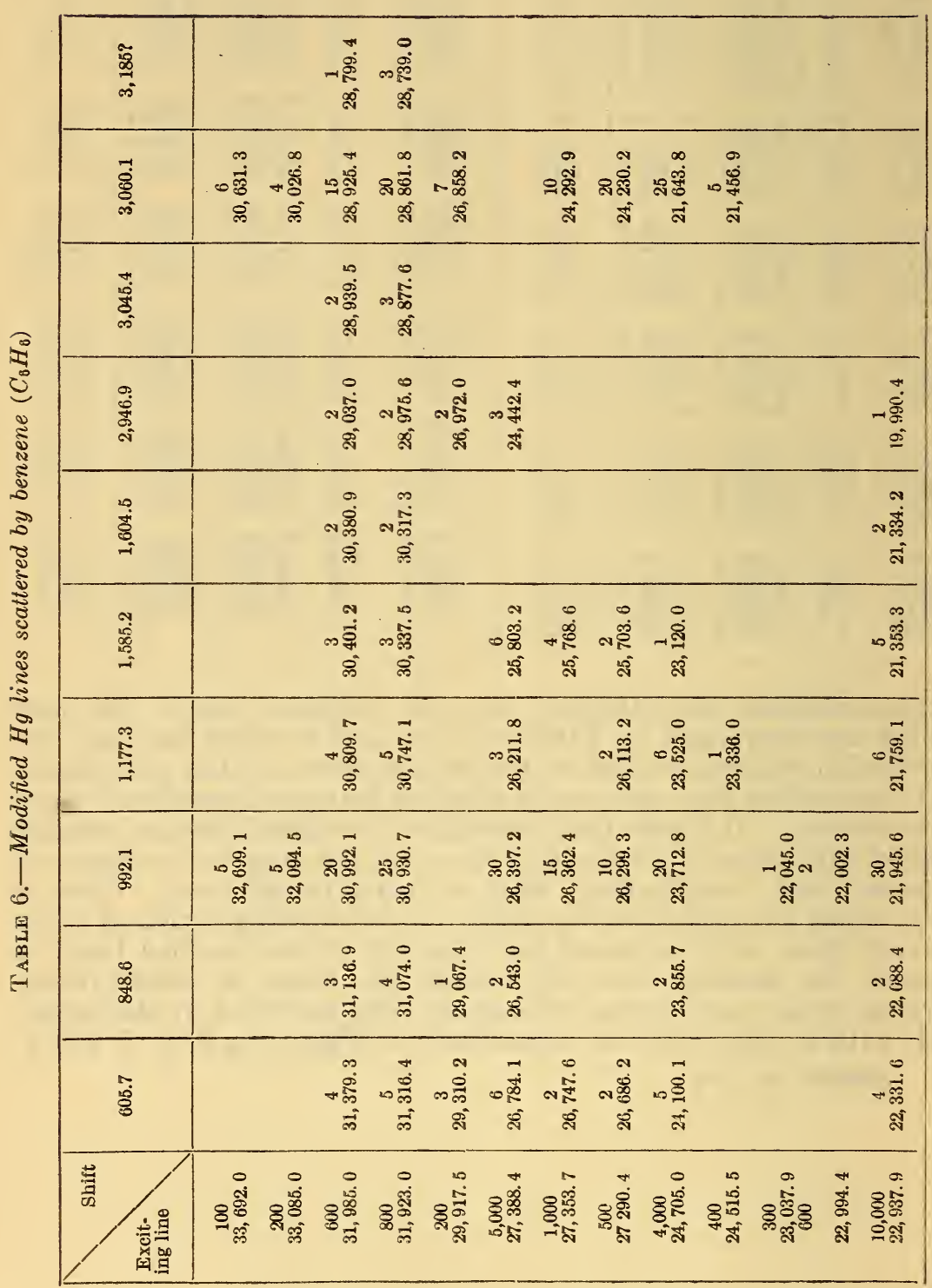




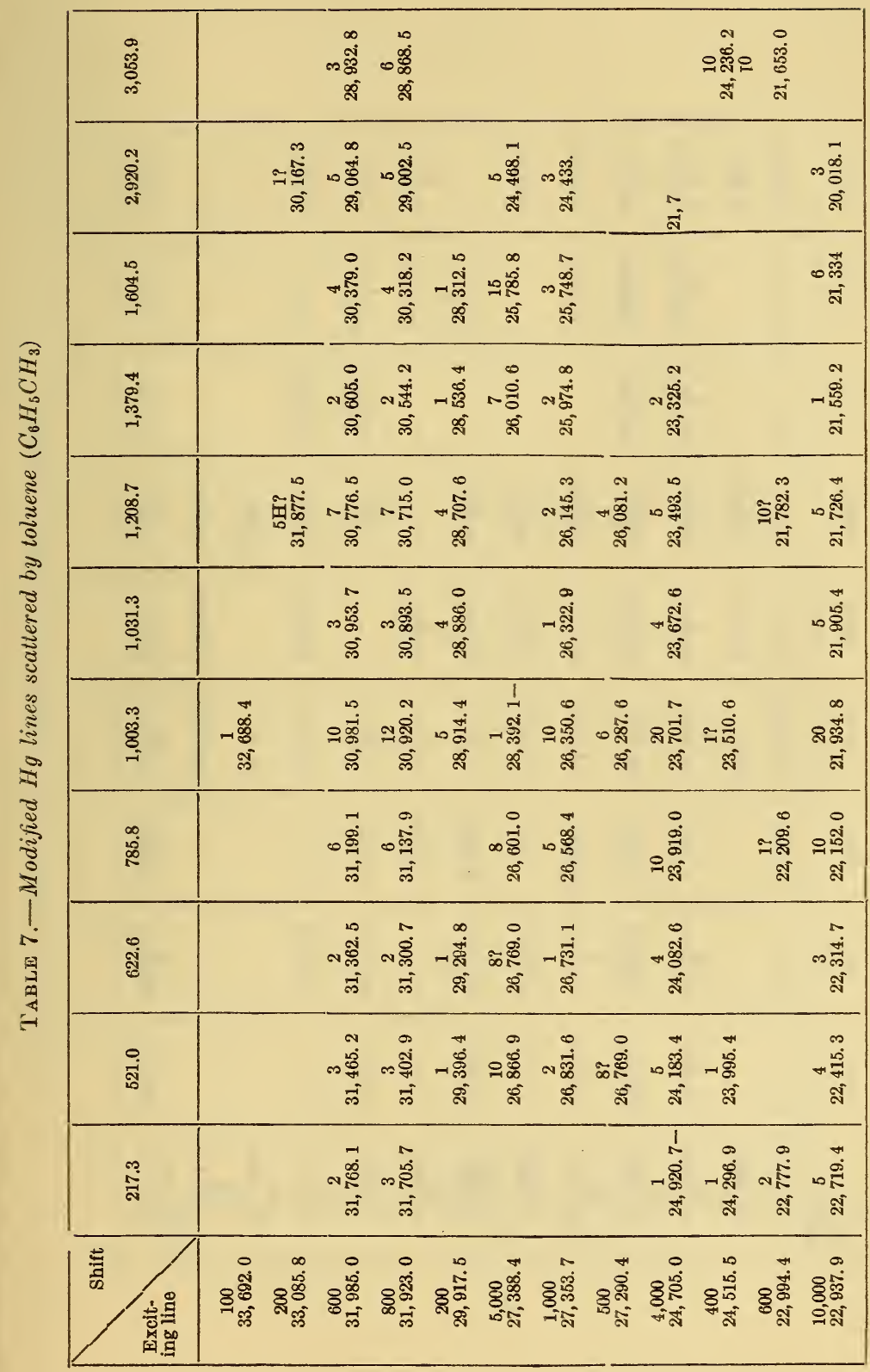




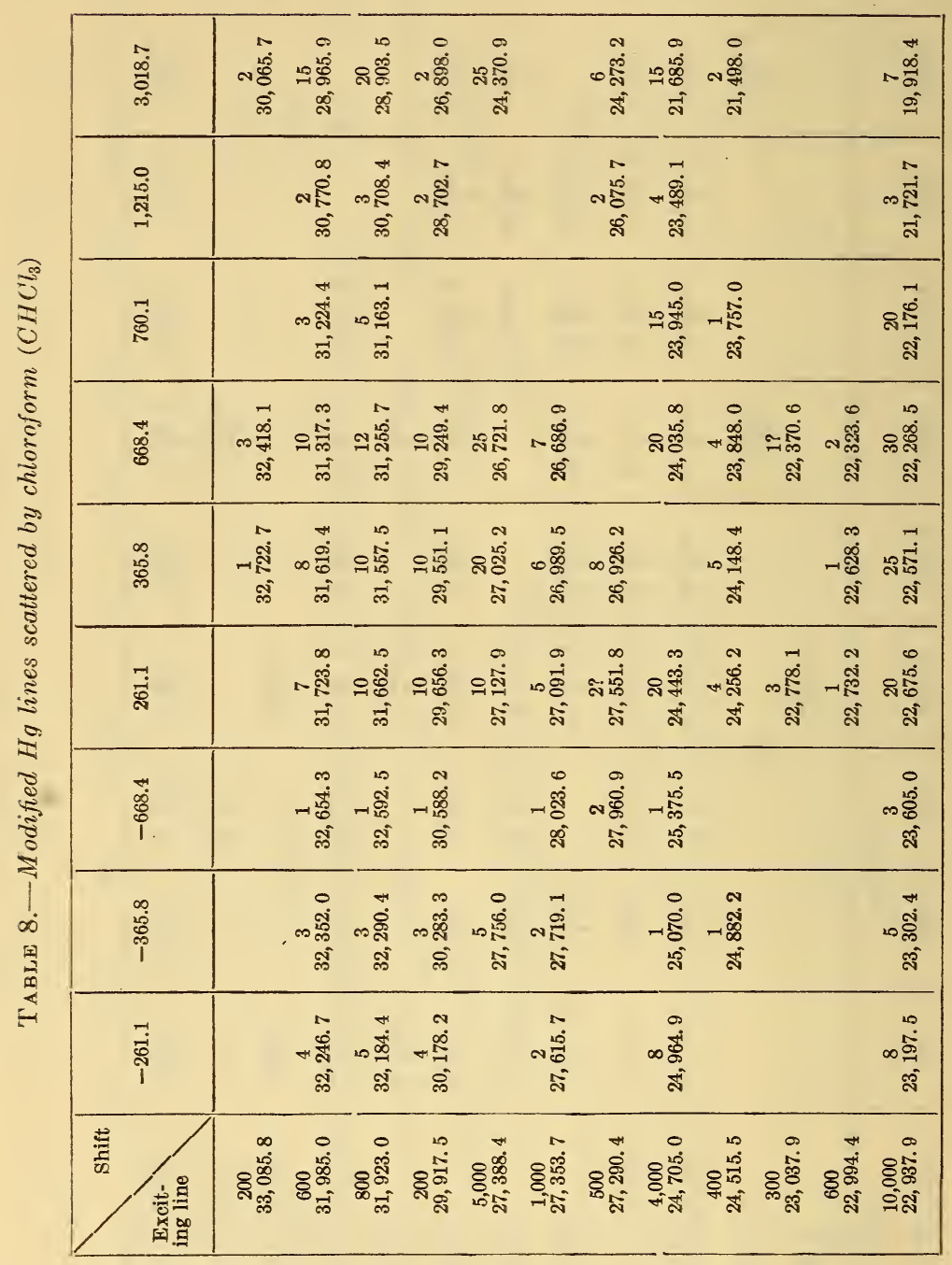




\begin{tabular}{|c|c|}
\hline 总 & - \\
\hline 迥 & 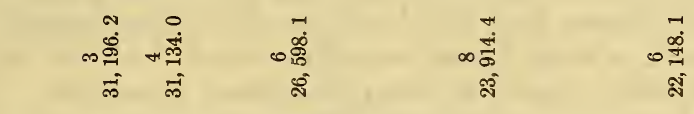 \\
\hline of & 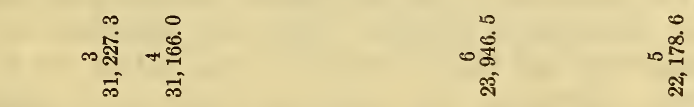 \\
\hline is & 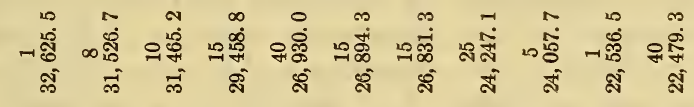 \\
\hline 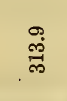 & 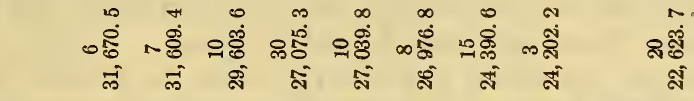 \\
\hline \begin{tabular}{l}
$\infty$ \\
$\stackrel{\infty}{\infty}$ \\
\multirow{2}{*}{}
\end{tabular} & 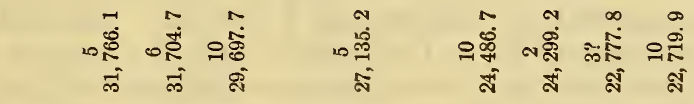 \\
\hline i़ & 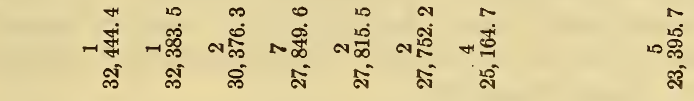 \\
\hline $\begin{array}{l}0 \\
\substack{0 \\
p}\end{array}$ & 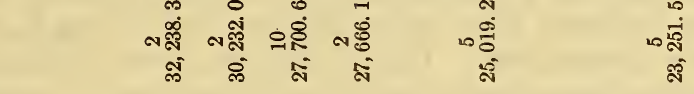 \\
\hline 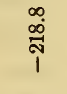 & 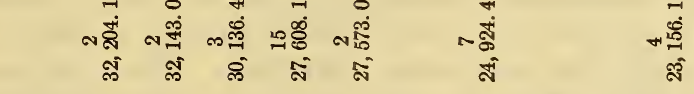 \\
\hline & 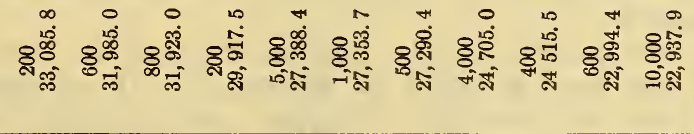 \\
\hline
\end{tabular}




\section{DISCUSSION}

It is now generally recognized that the interpretation of modified lines in scattered light is not so simple as was first supposed. Many observers have already called attention to the fact that although some of the shifts of modified lines could be identified with lines in the infra-red absorption spectrum, the latter were not always represented (directly) in the spectrum of scattered light and the intensities did not agree. As an example, we may refer to benzene and toluene for which the most intense and sharpest modified lines are shifted 992 and $1,003 \mathrm{~cm}^{-1}$, respectively. Converting these shifts to infra-red wave lengths and comparing with the observed absorption spectra in the infra-red shows that the benzene shift corresponds (perhaps accidentally) with a very broad complex band, but the toluene shift has no corresponding band in its absorption spectrum. That a direct correlation between scattering shifts and absorption lines need not be expected on theoretical grounds was first pointed out by Langer ${ }^{18}$ and this reasoning has been further developed in the first part of the present paper. Perhaps the chief handicap for a complete interpretation of the phenomena of modified scattering at present is our meager knowledge of the absorption spectra characterizing complex molecules, and until more extensive and precise data on the molecular energy levels are available it is doubtful if the exact connection of such constants as are obtainable from experiments on scattered light with molecular structure can be established.

In conclusion we shall summarize what is known concerning the shifts of modified lines and the available data on infra-red absorption bands; the material is collected in Table 10. The infra-red absorption data are quoted from Coblentz, ${ }^{19}$ and the letters accompanying his wave lengths indicate the relative prominence of the various bands: $\mathrm{S}=$ strongest, $\mathrm{s}=$ strong, $\mathrm{m}=$ medium, $\mathrm{f}=$ faint. The relative intensities of the computed wave lengths $(1 ; \nu)$ are indicated by numbers (in parentheses) which represent the estimated intensities of the strongest "Stokes" lines observed.

Table 10 shows at a glance that the original theory of a direct correspondence between absorption spectra and shifts in scattered light is completely discredited. In fact, for the four liquids here discussed no exact coincidences occur and the approximate ones may be considered to be accidental, since, in general, the number of observed absorption lines in the interval studied greatly exceeds the number of frequency shifts in the same interval. Other liquids have been studied in which there is absolutely no correspondence, not even "approximate."

The fine structure of infra-red absorption in certain inorganic compounds has been studied by Barnes ${ }^{20}$ with an echellete of high resolving power so that wave lengths are obtainable with errors of measurement not exceeding $\pm 0.003 \mu$. Measurements of this type permit a more critical comparison of absorption data with wave

18 Langer, Nature, 123, p. 345; 1929.

${ }^{9}$ Coblentz, Investigations of Infra-red Spectra, Carnegie Institution of Washington Publication No. 35, 1905.

${ }_{20}$ Barnes, Nature, 124, p. 300; 1929. 


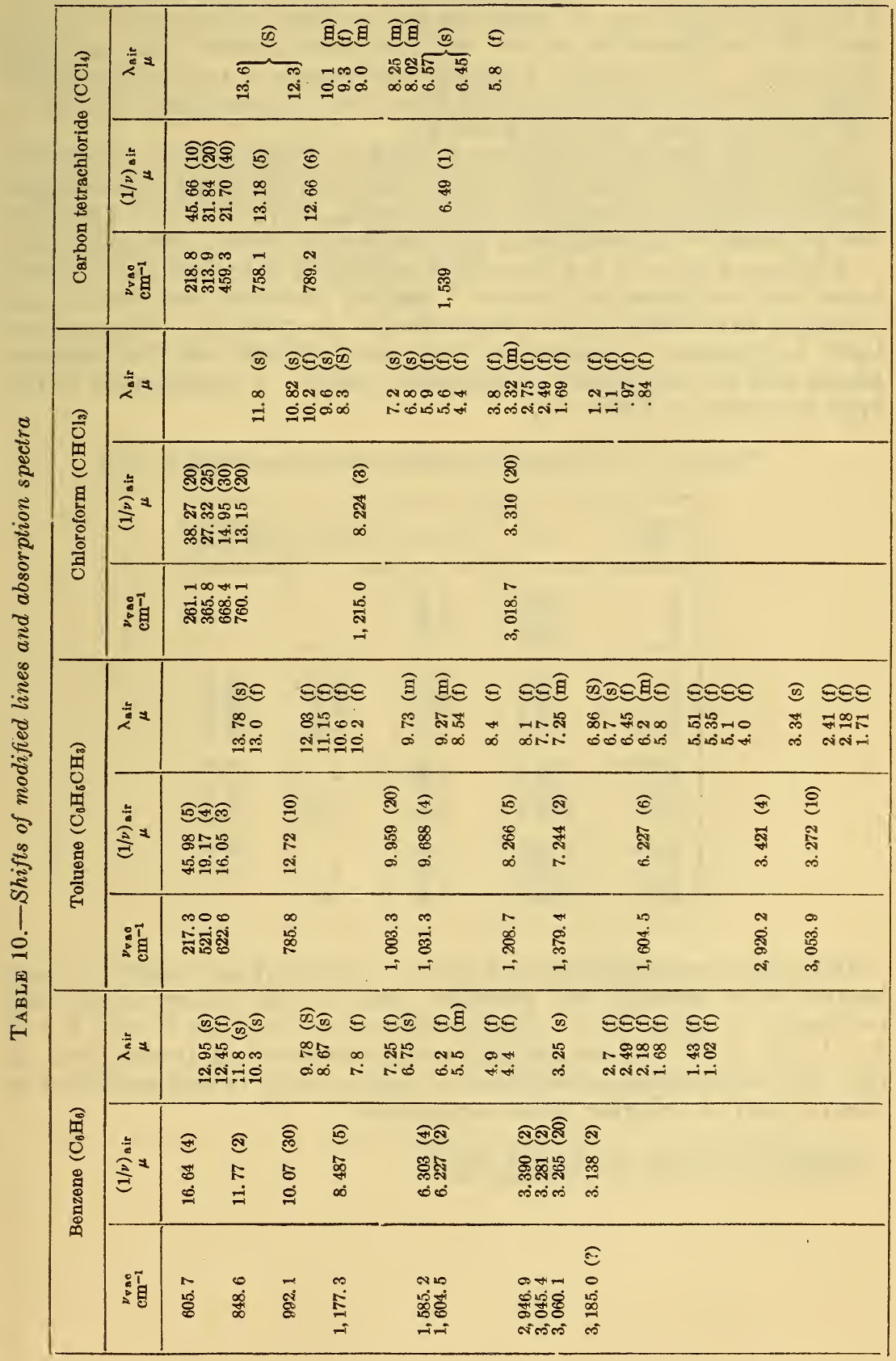


lengths calculated from frequency shifts for scattered light. Thus, Barnes observes in benzene three bands of equal intensity at $3.231 \mu$, $3.253 \mu$, and $3.291 \mu$. In scattered light we observe 3.265 (20), 3.281 (2), 3.390 (2), the first two of which are near the last two given by Barnes, but still the differences are two or three times greater than the probable errors. Furthermore, a serious discrepancy in relative intensities exists, and no scattered light is observed corresponding to $3.231 \mu$ and no absorption line for $3.390 \mu$.

In toluene Barnes has observed bands at $3.238 \mu, 3.261 \mu, 3.278 \mu$, $3.298 \mu, 3.343 \mu, 3.428 \mu, 3.478 \mu$, and $3.481 \mu, 3.298$ being the strongest. Scattering experiments give, in this region, $3.272(10)$ and $3.421(4)$; one is forced to the conclusion that there is no direct correspondence.

Additional data on the absorption spectrum of carbon tetrachloride have been published by Marvin ${ }^{21}$ and by Coblentz and Stair ${ }^{22}$ and attempts have been made to reconcile the observations with scattered light frequencies by assuming that part of them are fundamental bands and the remainder combination bands. A comparison of this type is shown in Table 11.

TABLE 11.-Calculated and observed absorption bands in $\mathrm{CCl}_{\mathbf{4}}$

\begin{tabular}{|c|c|c|c|c|}
\hline$\underset{\text { tion }}{\text { Combina- }}$ & $\nu_{\mathrm{V} \text { ao }}$ & $(1 / \nu)_{\text {air }}$ & (Marvin) & $\begin{array}{l}\text { (Coblentz } \\
\text { and Stair) }\end{array}$ \\
\hline $\begin{array}{l}\mathrm{A} \\
\mathrm{B} \\
\mathrm{C} \\
\mathrm{A}+\mathrm{C}\end{array}$ & $\begin{array}{l}218.8 \\
313.9 \\
459.3 \\
678.1\end{array}$ & $\begin{array}{l}45.66 \\
31.84 \\
21.70 \\
14.74\end{array}$ & 14.89 & \\
\hline $\begin{array}{l}\mathrm{D} \\
\mathbf{E} \\
\mathrm{A}+\mathbf{D} \\
\mathbf{A}+\mathbf{E}\end{array}$ & $\begin{array}{r}758.1 \\
789.2 \\
976.9 \\
1,008.0\end{array}$ & $\begin{array}{r}13.18 \\
12.66 \\
10.23 \\
9.92\end{array}$ & $\begin{array}{r}13.09 \\
12.73 \\
10.21 \\
9.94\end{array}$ & $\begin{array}{r}13.10 \\
12.67 \\
10.22 \\
9.95\end{array}$ \\
\hline $\begin{array}{l}\mathrm{B}+\mathrm{B}+\mathrm{C} \\
\mathrm{B}+\mathrm{E} \\
\mathrm{C}+\mathrm{D} \\
\mathrm{C}+\mathrm{E}\end{array}$ & $\begin{array}{l}1,087.1 \\
1,103.1 \\
1,217.4 \\
1,248.5\end{array}$ & $\begin{array}{l}9.20 \\
9.06 \\
8.21 \\
8.01\end{array}$ & $\begin{array}{l}9.13 \\
8.24 \\
7.99\end{array}$ & $\begin{array}{l}9.32 \\
9.08 \\
8.20 \\
8.02\end{array}$ \\
\hline $\begin{array}{l}\mathrm{D}+\mathrm{D} \\
\mathrm{F}+\mathrm{E} \\
\mathrm{E}+\mathrm{F}\end{array}$ & $\begin{array}{l}1,516.2 \\
1,539.0 \\
1,547.3 \\
2,328.0\end{array}$ & $\begin{array}{l}6.59 \\
6.50 \\
6.46 \\
4.29\end{array}$ & $\begin{array}{l}6.47 \\
4.31\end{array}$ & $\begin{array}{l}6.57 \\
6.45\end{array}$ \\
\hline
\end{tabular}

Here the average difference between calculated and observed wave lengths also exceeds the probable error of the observations, and no reason is given why other combinations such as $\mathrm{C}+\mathrm{C}, \mathrm{E}+\mathrm{E}$, $\mathrm{A}+\mathrm{A}+\mathrm{C}, \mathrm{A}+\mathrm{B}+\mathrm{C}$, etc., should not be observed in absorption. In fact, the combination possiblities are large enough to cast suspicion on this method of bringing about agreement.

${ }_{21}$ Marvin, Phys. Rev., 34, p. 161; 1912; 33, p. 952; 1929.

a Coblentz and Stair, Phys. Rev., 33, p. 1092; 1929. 
At this point attention is called to the fact that the energy diagram for $\mathrm{CCl}_{4}$ previously published by one of us ${ }^{23}$ made use of data less accurate than those in the present paper. This means that various levels in the diagram must be shifted slightly. The agreement with infrared absorption data, however, is not materially affected by these changes.

It seems futile to attempt at present a complete interpretation of the modified lines scattered by liquids, or to draw any final conclusions as to molecular structure from them. The systematic accumulation of reliable data for scattering substances belonging to distinct chemical families, and especially the investigation of the simpler molecular structures may be expected to give clues to the correct explanation of light scattering in transparent media.

Washington, October 1, 1929.

${ }_{23}$ Langer, Nature 123, p. 345; 1929. 